\title{
An Advanced Design Procedure for the Safe USE of Steel Storage Pallet Racks in Seismic Zones
}

\author{
Claudio Bernuzzi and Marco Simoncelli \\ Department of Architecture, Built Environment and Construction Engineering \\ Politecnico di Milano, Milano-Italy
}

\begin{abstract}
Industrial steel storage pallets racks represent one of the most economical solutions for storing goods and products when space is limited. This well-recognized convenience is however counterbalanced by a structural response that is generally complex to predict, especially under earthquakes. The design procedures adopted worldwide do not seem to take adequately into account for the key features associated with these structures. From the engineering point of view, racks are designed as moment-resisting steel frames but of an unconventional type because they are characterized by an extensive use of thin-walled cold-formed members. Furthermore, the overall dynamic response is often greatly affected by a non-negligible deterioration of the joint behavior due to large excursions in the plastic range, with the direct consequence that the load carrying capacity is reduced.

In this paper, the well-established non-linear time-history (NLTH) method of analysis is combined with the low-cycle fatigue (LCF) damage approach in order to 1) investigate the damage distribution, 2) assess the residual fatigue life and 3) estimate the effective load-carrying capacity after an earthquake. In particular, key open problems related to the seismic design of racks are identified and the NLTH-LCF procedure is introduced and discussed. Finally, attention is focused on a practical case study related to a medium-rise doubly-entry pallet rack. Reference is made to two recent Italian earthquakes and two models have been adopted to reproduce the cyclic joint behavior of beam-to-column joints allowing for a direct appraisal of its influence on the overall rack response.
\end{abstract}

Keywords: steel storage pallet racks, moment-resisting frames, non-linear time-history analysis $(N L T H)$, damage index, low-cycle fatigue (LCF), residual life, effective load carrying capacity.

\section{INTRODUCTION}

Thin-walled steel components formed from strips or coils by cold-rolling processes represent an important and growing area for the steel construction industry [1,2]. In addition to applications for civil engineering, their use has significantly increased for industrial storage applications, which is due to their high strength-to-weight ratio. Goods and products are frequently stored in steel racks, 
which can be distinguished [3] on the basis of the structural scheme and/or the picking modalities in warehouses (cladding racks), drive-in and drive-through rack systems, shuttle racks, gravity racks and adjustable selective storage pallet racks, which are the core of the present paper. The typical geometric layout of pallet racks (Fig. 1), which in the following are simply identified as "racks", appears to be similar to that of the more conventional semi-continuous framed systems employed in civil and industrial steel construction. In particular, the vertical elements (uprights) are coupled in the transversal (cross-aisle) direction. They form a set of trussed (built-up) columns (upright frame) connected to each other in the longitudinal (down-aisle) direction by pairs of pallet beams directly supporting the stored units.

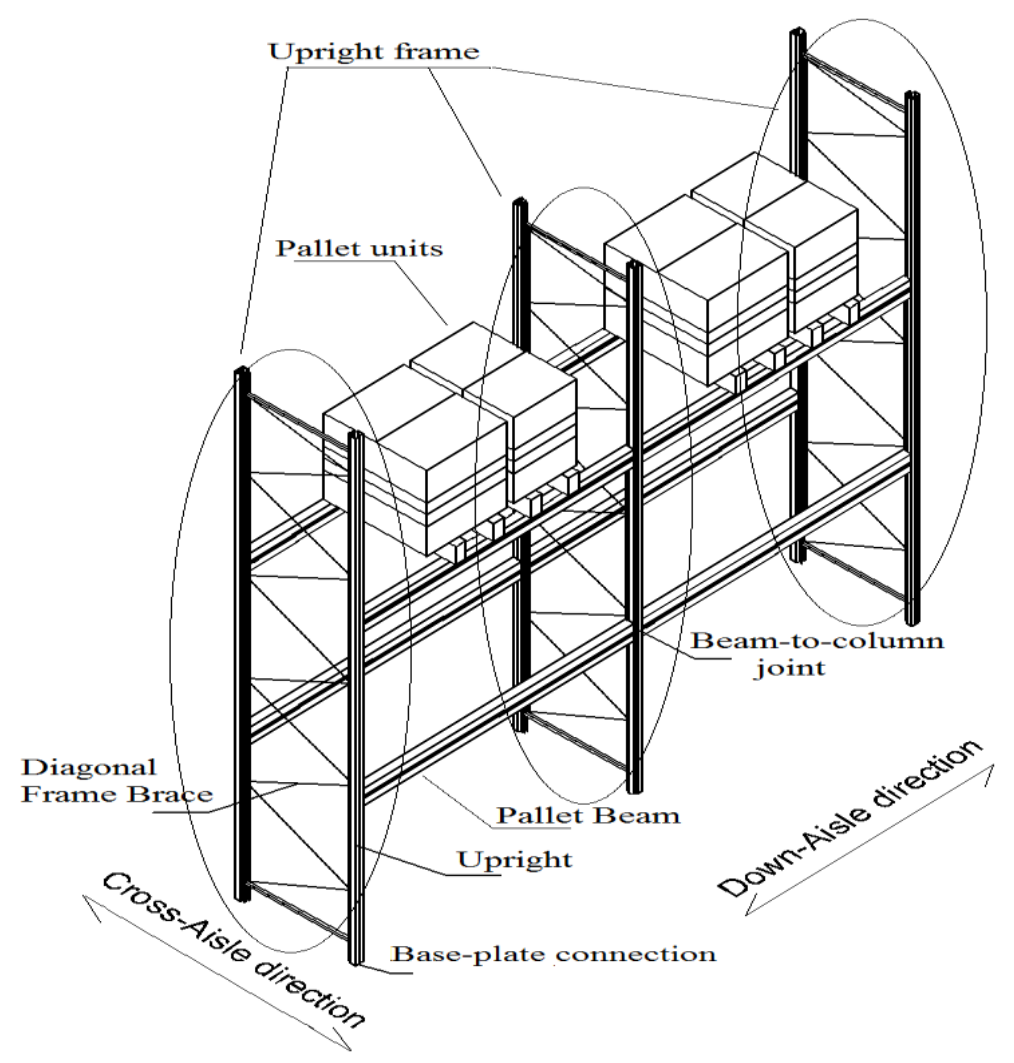

Figure 1. Typical pallet rack configuration.

The cost of the racks is typically low, due to their extremely reduced weight; however, their design is in general fairly complex, owing to the key features characterizing these structures. To this purpose, it is worth mentioning that:

- beam-to-column connections are in many cases without site bolts or site welds [4]. Pallet beams have at their ends a shop welded connector (bracket) with tabs and/or hooks to be accommodated in the perforation systems (special slots) regularly pitched along the uprights. These connection types are necessary to allow for the quick and easy assembly of the framed system as well as allowing for changes to the rack geometric layout during the 
in-service life. However, they provide only a very limited degree of lateral stiffness in the down-aisle direction [5];

- thin-walled cold-formed members are frequently used for uprights, pallet beams and diagonal members (lacings). Buckling phenomena governing the overall and local responses $[6,7]$ are quite difficult to predict, owing in part to the presence of the upright perforations, which have a significant influence on the overall structural performance;

- open cross-section members are frequently used, which are characterized by the presence of only one axis of symmetry. Owing to the non-coincidence of the shear center and the crosssection centroid, as discussed in literature [8-10], the effective member behavior can be captured accurately only by means of suitable finite element (FE) analysis packages offering the warping of the cross-section as an additional degree of freedom in the beam formulation [11-13].

Despite the efforts made in previous research [14-16] which have remarkably contributed to increasing the state-of-knowledge, there are several critical issues that need further investigation, especially for racks in seismic zones. This paper presents the first results of a study on the development of more refined design strategies. A procedure based on non-linear time-history (NLTH) analysis $[17,18]$ combined with the low-cycle fatigue (LCF) approach $[19,20]$ is introduced and applied to rack design. In particular, by adopting suitable constitutive joint laws, able to reproduce the experimental cyclic behavior, the damage of the components associated with each integration step can be directly assessed. This then allows for the evaluation of the total accumulated damage, the residual life and the rack performance post the earthquake. Furthermore, a case study related to a medium-rise storage rack is discussed in detail to better explain the key features of the proposed NLTH-LCF procedure. At the same time, the direct influence of the cyclic joint modelling on the effective rack load-carrying capacity after earthquake is shown.

\section{KEY FEATURES OF RACK DESIGN IN SEISMIC ZONES}

Remarkable differences can be observed if the more conventional steel framed buildings and the industrial systems are compared to each other. In particular, it is worth focusing attention on the following items:

- the dead-to-live load ratio. In buildings, live loads are always comparable with the dead loads while in racks, the weight of the structure is very limited, generally not greater than $5 \%$ of the total weight of the stored pallet units. The condition of fully loaded racks generally governs both static and seismic design. As a consequence, owing to the influence of the applied masses on the dynamic response of such flexible frames, rack performance in seismic zones is strictly dependent on the weight of the pallet units; 
- the joint behavior. Every type of beam-to-column rack joint is characterized by a response $[4,14]$ that has to be experimentally evaluated by the manufacturers in order to obtain the data on which base the structural design [21]. As an example, reference can be made to figure 2, where the joint behavior is expressed by means of the monotonic relationship between the moment $(M)$ corresponding to the bracket of the connection (i.e. at the face of the upright) and the relative rotation $(\Phi)$ between the upright and the pallet beam end. The figure depicts the experimental responses associated with three nominally equal specimens tested under hogging moments, according to the European design provisions for static rack design [22,23].
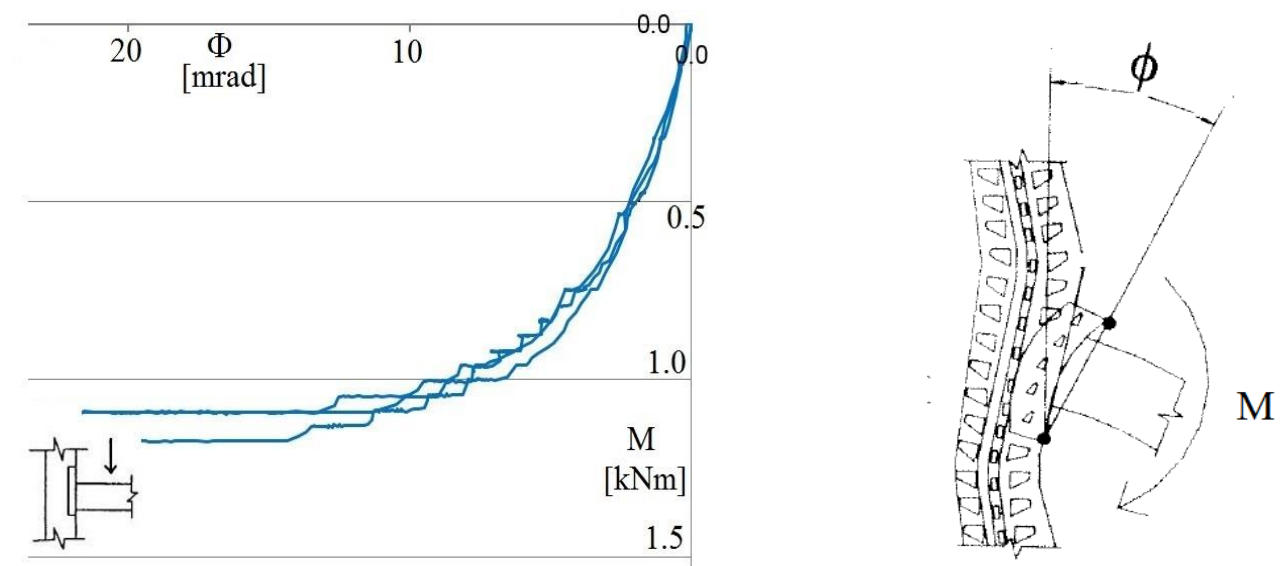

Figure 2. Definition of the moment-rotation curve for a typcal beam-to-column rack joint.

- the cross-section class. In racks, members generally belong to classes 3 or 4 in accordance with the EC3 classification criteria [24] because of the presence of open thin-walled crosssection and/or regular perforation systems. Member response is limited by the code to remain always in the elastic range, because these members cannot enter in plastic range producing a stable hysteretic behavior in terms of moment-curvature relationship (and thus, no energy dissipation);

- the dynamic response. In general, joints provide a limited degree of rotational stiffness and modest flexural resistance when compared with the flexural strength and stiffness of pallet beams. As a consequence, the high flexibility of racks to lateral loads results in high values of the fundamental period of vibrations $\left(\mathrm{T}_{1}\right)$, up to 3-4 s, that are typically observed for highrise and tall steel buildings. Furthermore, unlike in conventional buildings, the checks associated with the lateral displacements under earthquakes can often be neglected owing to the absence of non-structural elements that might be damaged (i.e. partitions and cladding panels) by the lateral displacement induced by ground motions. 
As far as seismic design is concerned, it appears that racks behave like moment-resisting frames where only beam-to-column joints and base-plate connections are able to provide satisfactory behavior in the post-elastic range. In Europe, as well as in other countries, reference is made to the FEM 10.2.08 recommendations [25] and to the prEN16681 provisions [26] which, after the public inquiry phase, are now in the process of being approved as EN standards. Both of them derive strictly from the provisions governing the design of the more conventional steel frames, despite the aforementioned non-negligible peculiarities of racks. In more detail, different methods of analysis can be adopted in seismic zones [27] and the methods most commonly used by rack designers are the lateral force method of analysis (LFMA) and modal response spectrum analysis (MRSA). A common open problem is the value of the behavior $\left(q^{-}\right)$factor, that is the number scaling the elastic response spectrum (ES) to the design spectrum (DS). Both spectra are shown in figure 3 in terms of relationship between the peak ground acceleration $a_{g}$ normalized by the acceleration due to gravity (g) versus the period $T$.
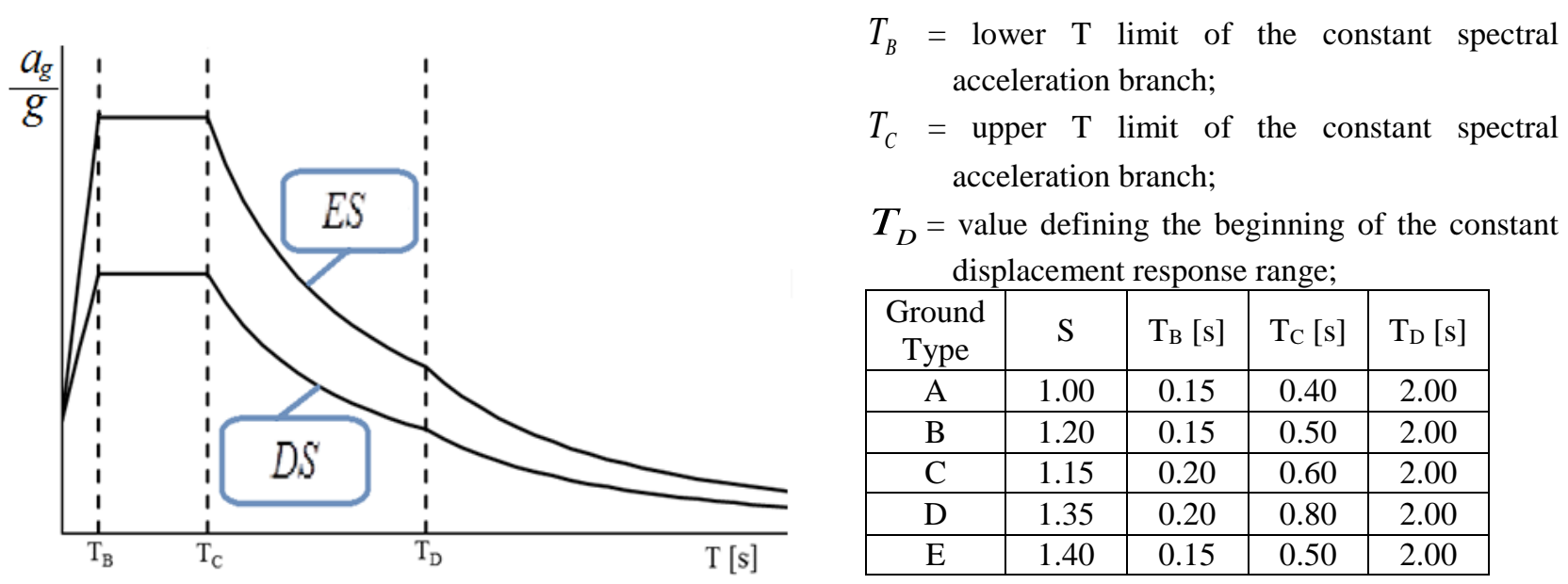
acceleration branch;

$T_{C}=$ upper $\mathrm{T}$ limit of the constant spectral acceleration branch;

$T_{D}=$ value defining the beginning of the constant displacement response range;

\begin{tabular}{|c|c|c|c|c|}
\hline $\begin{array}{c}\text { Ground } \\
\text { Type }\end{array}$ & $\mathrm{S}$ & $\mathrm{T}_{\mathrm{B}}[\mathrm{s}]$ & $\mathrm{T}_{\mathrm{C}}[\mathrm{s}]$ & $\mathrm{T}_{\mathrm{D}}[\mathrm{s}]$ \\
\hline $\mathrm{A}$ & 1.00 & 0.15 & 0.40 & 2.00 \\
\hline $\mathrm{B}$ & 1.20 & 0.15 & 0.50 & 2.00 \\
\hline $\mathrm{C}$ & 1.15 & 0.20 & 0.60 & 2.00 \\
\hline $\mathrm{D}$ & 1.35 & 0.20 & 0.80 & 2.00 \\
\hline $\mathrm{E}$ & 1.40 & 0.15 & 0.50 & 2.00 \\
\hline
\end{tabular}

Figure 3. Typical elastic response spectrum according to EC8 [28].

European rack provisions do not give rules to assess $q$ but they clearly state that it cannot be greater than 2 for non-dissipative structural behavior and rack designers generally assume $q=2$, which is the most favorable value permitted. This approach neglects all the various factors influencing the seismic response, such as the geometric layout, the performance of the rack components (members and joints) and the value of the pallet unit weight. This, in the authors' opinion, leads to an unsafe and/or non-optimal design. So, what is the most appropriate value of the behavior factor to adopt according to LFMA and/or MRSA seismic design approaches? In accordance with seismic steel provisions, one of the following three q-values should be permitted: $1,1.5$ or 2 , each of them fully consistent with the standard requirements. Unity could be conservatively assumed because uprights and pallet beams, as previously mentioned, are in class 3 or 4, i.e. they are not able to dissipate energy through hysteretic behavior. This value is also justified by the very limited capacity of the 
joints to dissipate energy and by the presence of slender elements resisting both compression and tension forces (for example the lacings of the upright frames) for which no reduction of the elastic spectrum is permitted [29]. Furthermore, $\mathrm{q}=1.5$, which is the lowest limit value recommended by EC8 [28], could at least seem reasonable for racks. This is because design strengths are based on the characteristic material properties, which are typically 5\% fractal values, and are used in combination with both component test results [21] and material strength reduction factors. Moreover, $\mathrm{q}=1.5$ should represent a simplified way of acknowledging that there is some level of conservatism in the equations used to predict component resistance. Finally, q=2 could be assumed because it is, as already mentioned, the upper limit permitted by the European rack provisions $[25,26]$ for low ductile behavior. It is worth mentioning that, from a practical point of view, the assumption of $\mathrm{q}=2$ instead of $\mathrm{q}=1.5$ (or equivalently $\mathrm{q}=1.5$ instead of $\mathrm{q}=1$ ) should lead to significant differences (up to two times) in the value of the seismic load carrying capacity.

Furthermore, despite the relevant research efforts to improve the rules for routine rack design, several additional critical issues need further investigation. Findings of such investigations should be urgently included in the guidelines and/or provisions for manufacturing engineers. Among them, it is worth mentioning the influence of the cyclic joint response on the overall seismic rack behavior. In particular, a very unstable behavior of beam-to-column joints has been experimentally observed [30-33] when reversing moments are applied, as occurs during earthquakes. For example, reference can be made to figure 4, which is related to an experimental study [33] on two types of beam-to-column joints (named as A- and B-type), produced by two Italian rack manufactures and differing in terms of the geometric details (hooks and slots) of the connection device.
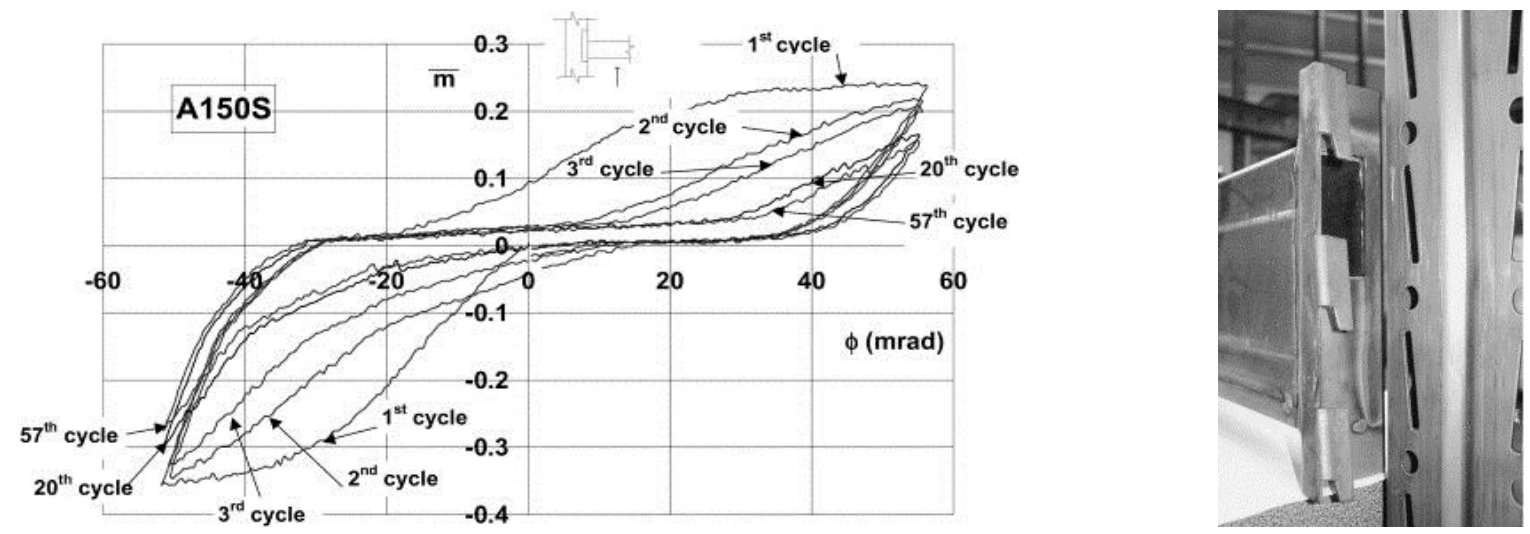

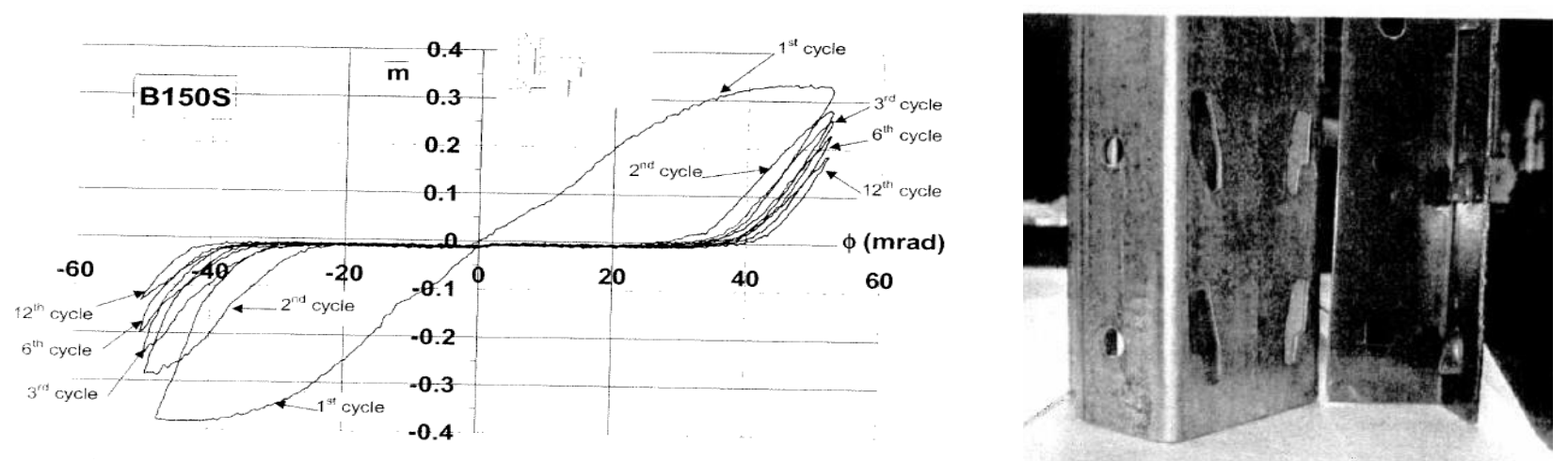

Figure 4. Examples of cyclic moment-rotation curves for beam-to-column rack joints [33].

The moment-rotation cyclic curves are depicted for some selected cycles and the joint moment $\left(M_{j}\right)$ is presented in a non-dimensional form $(\bar{m})$ by dividing it by the pallet beam flexural resistance $\left(M_{R d, p b}\right)$, i.e. $\bar{m}=M_{j} / M_{R d, p b}$. It can be noted that the first cycle is always quite stable and regular. It is therefore qualitatively similar to the behaviour associated with more conventional steel frames joints [34]. In the subsequent cycles, a progressive and regular deterioration of the rotational stiffness and flexural strength can be noted. This is due to the increase of the amplitude of the zone that is influenced by the yielding of the outermost hooks in a progressive sequence towards the neutral axis of the pallet beam. The envelope of the cyclic joint response is quite coincident with the monotonic curve but the form of the hysteresis loop changes significantly after the first cycle, due to the strong influence of the residual deformations of the connection devices. In the case of joint A, the moment-rotation curve is characterised by loops in which the stiffness of the reloading branches decreases progressively with the evolution of the test, hence resulting in a non-negligible pinching. Otherwise, for joint $\mathrm{B}$, cycles subsequent to the first have an initial branch with essentially zero stiffness (slippage). The extent of slippage increases with progressive cycles and is followed by a reloading stiffness (after slippage) that is practically constant. Slippage, pinching and the reduction of stiffness and strength are expected to reflect on the overall rack performance after an earthquake. In particular, the first phenomenon significantly affects the amplitude of the total (sway) frame design imperfections, being them associated with a conventional out-of-plumb design angle of the upright (in general, equal to $3 \mathrm{mrad}$, approximately) and with the looseness of beam-to-column joints determined via a specific test on beam-end-connectors. Furthermore, the remaining phenomena could lead to two different effects. First, the increase of the flexibility to lateral loads increases significantly the sensitivity of the rack to second-order effects, reducing the buckling critical load and at the same time increasing the fundamental period of vibration. Second, the reduction of the joint performance increases the sagging moments and the deflections of the pallet 
beams under gravity loads, with a possible decrease of their load carrying capacity. Benefits could however be observed in terms of a reduction of the down-aisle bending moments on the uprights. Furthermore, practical guidelines should be proposed for rack manufacturing engineers to solve two critical questions affecting the safe in-service use of racks, such as:

- could plasticity in joints be neglected on a reliable evaluation of the performance of racks? When seismic excitations cause plasticity in the joints due to the applied reversal moments, failure and/or relevant accumulated damages due to low-cycle fatigue may occur, as already extensively observed in the components of the more conventional steel framed buildings. Furthermore, an accurate appraisal of the residual life of the joints should be necessarily for the safe use of the rack during the entire in-service life (a few decades);

- how to appraise the actual rack performance after the earthquake? As already mentioned, a critical aspect of the seismic design is the definition of the load carrying capacity, strictly depending on the aforementioned factors. After each of the earthquakes which could occur during the entire rack life, plastic deformation of joints could be associated with a reduction in stiffness and/or strength. Thus there is the need to assess the effective post-earthquake rack performance, which could be significantly different from that of the undamaged rack.

Both the LFMA and MRSA approaches are based on structural analyses requiring the knowledge only of the monotonic $M-\Phi$ joint response (figure 4). As a consequence, they suffer from the considerable defect of neglecting the stiffness and strength degradation (figure 2) characterizing the response of rack joints under earthquake excitations. From the practical point of view, a reduction of the overall rack performance is hence expected. Furthermore, the number of excursions in the plastic range and/or the values of the associated rotations never enter into the design approaches currently adopted, which assume an unlimited fatigue resistance. The same critical issues affect also the non-linear static pushover analysis (NSPA) design method in which lateral forces applied to the system are increased monotonically, i.e. once again neglecting the actual cyclic joint behavior. From the design point of view, pallet racks behave like moment-resisting frames where inelastic behavior can be observed only in the joints. As a consequence, the LFMA, MRSA and NSPA design approaches do not seem reliable for practical design purposes when applied to racks. An efficient design procedure should assess and monitor, at least, the following key features, which in the authors' opinion are of paramount importance to achieve the goal of a safe in-service use of racks:

- the accumulated damage in each critical component (beam-to-column joints and/or baseplate connections);

- the effective rotational stiffness and/or the moment resistance of joints; 
- the actual load carrying capacity after one or more earthquakes.

As confirmed in the following by the proposed case study, these items, which are currently always neglected in routine design procedures, could significantly affect the safe in-service use of the rack as well as more conventional steel frames made by hot-rolled profiles.

\section{THE PROPOSED NLTH-LCF DESIGN PROCEDURE}

An open problem affecting cold-formed storage rack design is represented by the design procedure to adopt for the member verification checks, independently of the loading type (seismic or static). This topic, which is beyond the scope of the present paper, has already been discussed in [35] showing that the approaches currently proposed by European rack provisions $[22,23]$ could lead to different assessments of rack performance. If attention is focused on the ultimate limit states, which are the ones generally governing rack design, a promising European approach is the so-called General Method [36,37], which is able to provide results that are fully consistent with those obtained via the US rack design procedures [38,39] and for this reason seems to be the more reliable. In particular, on the basis of the generalized set of internal forces, the safety of the whole rack is guaranteed when:

$$
S I=\frac{\gamma_{M}}{\chi_{o p} \alpha_{u l t, k}} \leq 1
$$

where $\alpha_{u l t, k}$ is the minimum load multiplier based on the resistance of the members and joints, $\chi_{o p}$ is the buckling reduction factor (in reference to the overall structural system), $\gamma_{M}$ is the material safety factor and SI represents the value of the safety index.

In particular, in the case of a beam-column subject to axial force $\mathrm{N}_{\mathrm{Ed}}$ and bending moments along the principal direction $\mathrm{M}_{\mathrm{y}, \mathrm{Ed}}$ and $\mathrm{M}_{\mathrm{z}, \mathrm{Ed}}$, the ultimate load multiplier for member resistance, $\alpha_{u l t, k, m}$ is the minimum of all the key rack components and it can be appraised as:

$$
\frac{1}{\alpha_{u l t, k, m}}=\left(\frac{N_{E d}}{\frac{A_{e f f} \cdot f_{y}}{\gamma_{M 0}}}+\frac{M_{y, E d}}{\frac{W_{e f f, y} \cdot f_{y}}{\gamma_{M 0}}}+\frac{M_{z, E d}}{\frac{W_{e f f, z} \cdot f_{y}}{\gamma_{M 0}}}\right)
$$

where $A_{\text {eff }}$, is the effective cross-section area and $W_{\text {eff, } y}$ and $W_{\text {eff } z}$ are the effective section moduli, along the principal directions, $f_{y}$ is the yield strength and $\gamma_{M O}$ is the safety coefficient.

Furthermore, indicating with $M_{j, E d}$ and $M_{j, R d}$ the design bending moment acting on the more stressed joint and its flexural resistance, respectively, the associated minimum joint ultimate load multiplier $\alpha_{u l t, k, j}$ is expressed as: 


$$
\frac{1}{\alpha_{u l t, k, j}}=\frac{M_{j, E d}}{M_{j, R d} / \gamma_{M 2}}
$$

where $\gamma_{M 2}$ is the safety coefficient.

It is worth mentioning that, in case of NLTH analysis, this method can be applied by excluding joints from the verification checks, with their non-linear behavior directly taken into account in the structural analyses.

Serviceability limit states should govern mainly the monotonic design and have to be referred to the pallet beams, requiring, in general, checks on both deflection and twist angle. Owing to the need to reduce the number of parameters affecting research outcomes, attention is herein focused only on components having two axes of symmetry and hence the condition governing design, which is associated with the vertical displacements, can be expressed as:

$$
\delta_{P B} \leq \delta_{L}
$$

where $\delta_{P B}$ is the maximum beam deflection while $\delta_{L}$ is the maximum admitted serviceability displacement depending on the rack class [40].

As far as seismic design is concerned, on the basis of the previous remarks, it appears that the only approach adequate for designing safely and optimally racks remains the one based on non-linear time-history (NLTH) analyses [18,27], suitably improved, to account for low-cycle fatigue (LCF) effects and for the reduction of structural performance, if relevant. More in detail, as already discussed in literature with reference to the more conventional steel components, it is convenient to make reference to the fatigue failure prediction function via the S-N line approach for high-cycle fatigue [41,42], that has already been extensively validated for low-cycle fatigue [19]. As can be observed in figure 5, the transition between the safe and unsafe zones can be expressed by the wellestablished Wholer's theory [43] as:

$$
N S^{m}=K
$$

or, equivalently, in the log-log domain:

$$
\log (N)+m \log (S)=\log (K)
$$

where $N$ is the number of cycles to failure at the constant stress (strain) range $S$ and $m$ identifies the slope of the line, distinguishing safe and unsafe regions, in a log-log scale. 


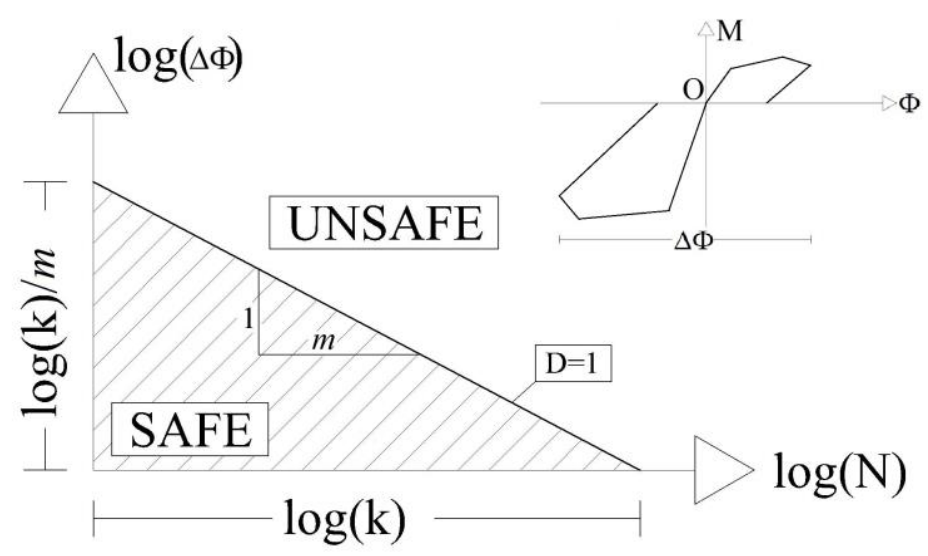

Figure 5. Fatigue resistance line in $\log (S)-\log (N)$ space.

In this research, reference is made to the Bernuzzi et al. [20] proposal for components of conventional steel frames and, in particular, owing to the role of paramount importance played by joints in racks, it has been assumed that the parameter $\mathrm{S}$ is equal to the total rotation range $\Delta \Phi$ and $m=3$. Consequently Eq. (4) can be re-written in the form:

$$
N(\triangle \Phi)^{3}=K_{B C C}
$$

or, equivalently:

$$
\log (N)+3 \log (\Delta \Phi)=\log \left(K_{B C C}\right)
$$

where $\mathrm{K}_{\mathrm{BCJ}}$ is a constant depending on both joint details and material properties. This criterion only allows for the evaluation of the fatigue failure of the component of interest when it is subjected to constant amplitude loading history. In the case of variable amplitude loads, instead of $\Delta \Phi$ an effective equivalent rotation range value, $\Delta \Phi_{\text {eq }}$, has to be adopted, which is related to the constant loading history characterized by the same number of cycles $(n)$ [44] leading to the same damage. The term $\Delta \Phi_{\mathrm{eq}}$ is defined as:

$$
\Delta \Phi_{e q}=\left[\frac{1}{n} \sum_{i=1}^{n} \Delta \Phi_{i}{ }^{3}\right]^{\frac{1}{3}}
$$

where $\Delta \Phi_{i}$ is the total rotation range of each cycle of the variable amplitude loading history.

As to the cycle counting methods, i.e. the approaches to evaluate $\Delta \Phi_{e q}$, reference can be made to the rainflow procedure which is recommended by the European fatigue design code [44].

Furthermore, it should be of great interest for design purposes to measure the damage associated with each earthquake and/or with a set of subsequent seismic events. The so-called Miner's rule [45] could be conveniently applied also to rack components, making reference to the damage index $D$, which ranges from 0 (no damage) to 1 (failure for LCF), expressed as:

$$
D=\frac{n_{i} \cdot \Delta \Phi_{e q}^{3}}{K}
$$


As already mentioned, attention is herein focused on the NLTH analysis based approach and hence a set of appropriate accelerograms has to be selected according to the requirements of the seismic design provisions. For each accelerogram, after the modelling phase of the rack defining the geometric and mechanical properties of all the key components, the proposed procedure is comprised of the following steps:

I. execution of the non-linear time history analyses by considering both geometrical and mechanical non-linearities;

II. accurate analysis of the output data, evaluating the value of the safety index of each member via the selected design approach and the accumulated damage for each joint via the LCF design approach;

III. appraisal, at the end of the NLTH analysis, of the eventual deterioration of the joint behavioral parameters and re-assessment of the static load-carrying capacity of the rack. In fact, it could happen that rack is able to resist to earthquake but the seismic load does not fulfill the static verification checks carried out with the deteriorated joints.

Figure 6 presents the flow-chart of the combined design procedure for which the structural checks are executed via the General Method. In particular, after the selection of a suitable accelerogram, the starting point is the definition of a tentative seismic design load $W_{S E I S}$, which is usually expressed as a uniformly distributed load on pallet beams. Assuming that the earthquake takes a period of $t_{\max }$ seconds, which has to be divided into a suitable number of the integration steps $(\Delta \mathrm{t})$. After the NLTH the safety index of each member $\left(S I_{i}\right)$ and the accumulated damage of each joint $(D)$ are evaluated, checking that they do not exceed the unity. If unity is exceeded then $W_{S E I S}$ has to be suitably reduced and the analysis repeated. Otherwise if all the $S I$ or $D$ checks are fulfilled (i.e. they are never greater than unity), the rack is able to resist to the earthquake with the considered seismic design load. 


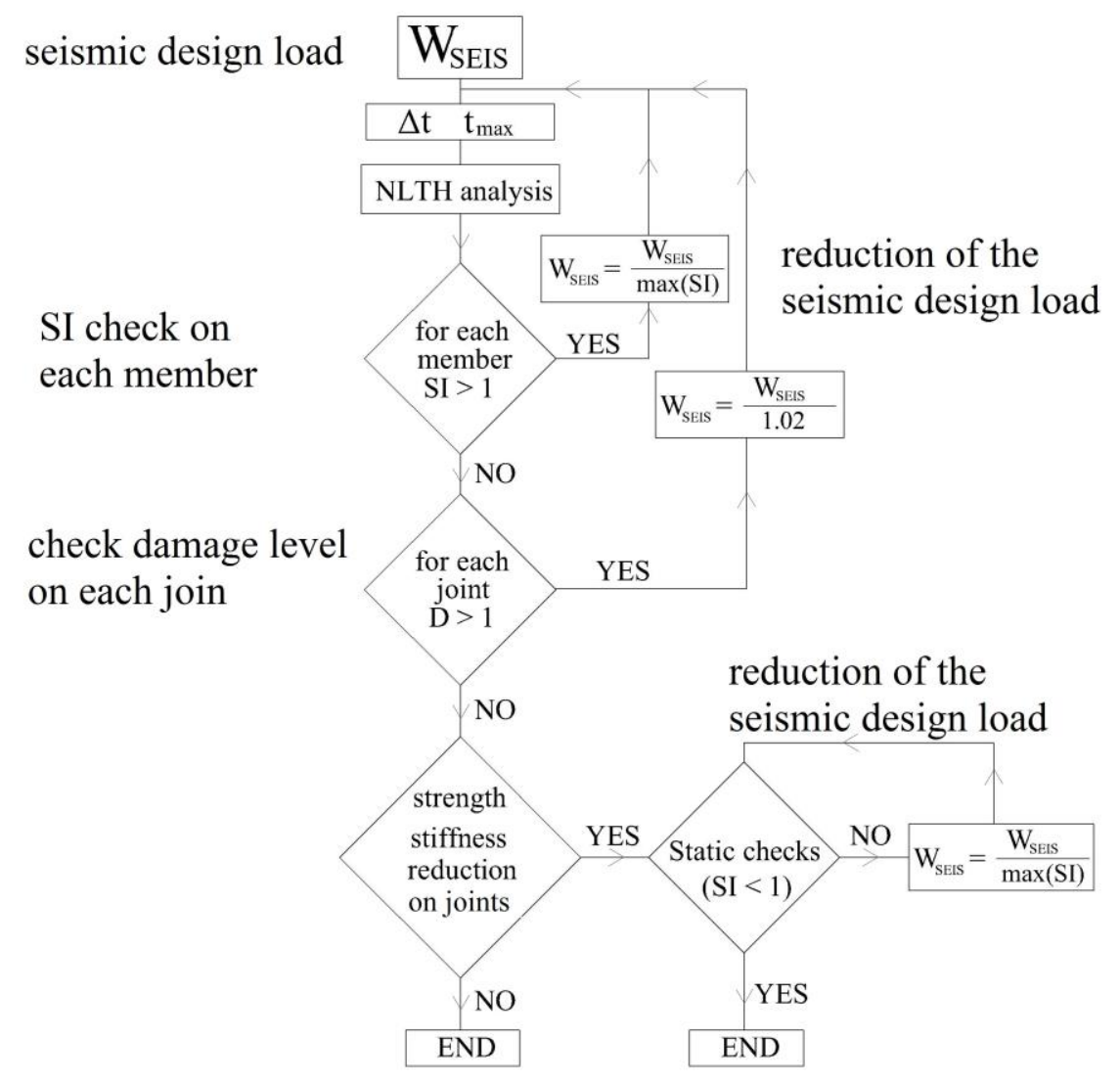

Figure 6. Flow-chart of the procedure.

It is worth noting that live loads (those associated with the masses of the stored units) have to be amplified by the factor $\gamma_{\mathrm{F}}$ according to the EN15512 [22], which assumes a value of 1.4 in the case of static design and 1.0 if seismic action is considered. From a practical point of view, once the value of the design load is defined, it is necessary to check, if the seismic load can be supported after the earthquake during the entire in-service life. From a practical point of view, if an earthquake weakens the joints then an evaluation under static load is necessary, with the performance updated to consider the updated strength and stiffness of the joints.

\section{APPLICATION OF THE NLTH-LCF PROCEDURE}

The combined NLTH-LCF design procedure discussed previously does not require advanced analysis tools because it can be applied using commercial FE non-linear analysis packages currently available in engineering offices.

\subsection{The case study}

For a deeper understanding of the potential of the proposed method, a case-study example is considered. The case-study is a six-bay four-story medium-rise double-entry pallet rack. The main details of the rack are sketched in figure 7, where the cross-section geometry of uprights, pallet 
beams and lacings are reported. Reference is herein made to racks constructed with uprights that have two axes of symmetry; however, the procedure is independent of the geometry of the components and hence is also valid for racks with only a single axis of symmetry, as well as for the more conventional steel frames comprised of hot-rolled members. All the components have rectangular or square hollow cross-sections and belong to class 3 according to the EC3 classification criteria [24]. The resulting class is due to the presence of intermediate stiffeners, which significantly reduce the influence of local buckling phenomena. Steel grades are S 355 for the uprights and S 235 for pallet beams and lacings, according to the EN 10025 provisions [46].

Storage levels have a constant inter-story height of $2.02 \mathrm{~m}$ ( which puts the upper most storage level at a height of $8.0 \mathrm{~m}$ ) and a bay length of $2.7 \mathrm{~m}$. The width of the upright frame is $1.10 \mathrm{~m}$.
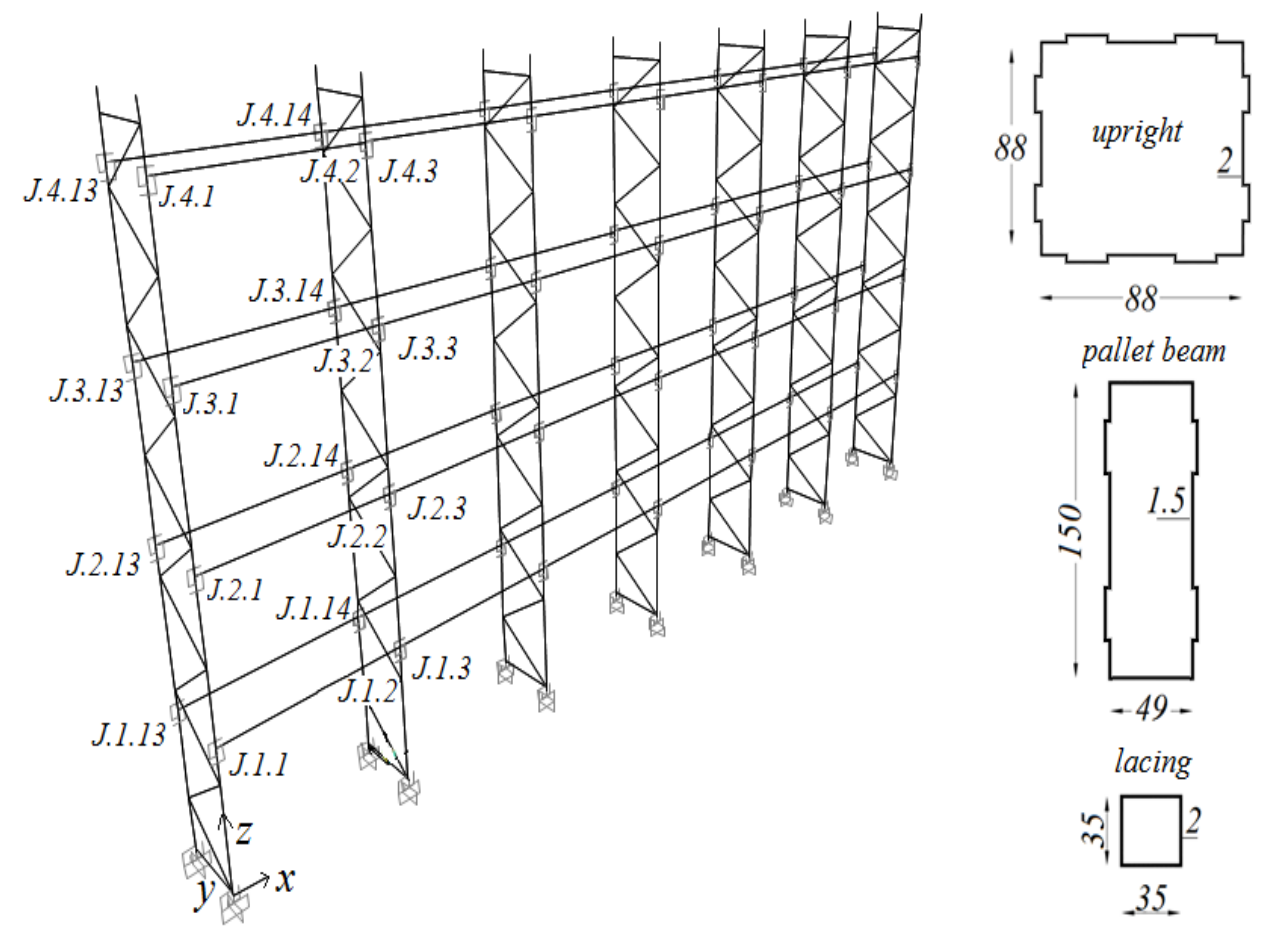

Figure 7. Detail of the considered rack with the transversal cross-section (dimensions are in millimeter).

Owing to the need to limit the number of variables affecting research outcomes, base-plate connections have been assumed to be perfectly fixed to the industrial floors supporting the rack. Furthermore, beam-to-column joints have been modeled by means of rotational springs, whose monotonic moment-rotation (M- $\Phi)$ constitutive law is presented in figure 8. In particular, accordingly to experimental studies [4], a different response has been considered for sagging (positive) and hogging (negative) bending moments. In both cases, a multi-linear relationship, comprised of softening branches, has been assumed. This is described in the table associated with figure, expressing the key points $\left(\mathrm{M}_{\mathrm{k}}, \Phi_{\mathrm{k}}\right)$ and the rotational stiffness $\left(\mathrm{S}_{\mathrm{k}}\right)$ of the linear branches. As 
occurs in normal rack practice, the joints exhibit superior behavior for hogging moment, which is a result of racks being generally designed for static loads.

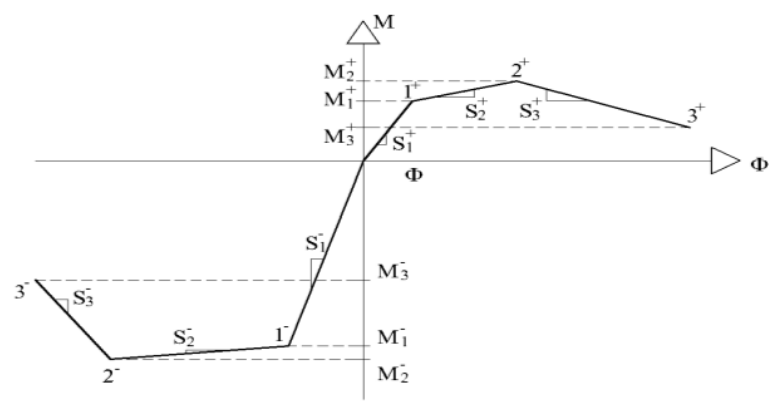

\begin{tabular}{|c|c|c|c|}
\hline point & $\mathrm{M}_{\mathrm{k}}[\mathrm{kNm}]$ & $\Phi_{\mathrm{k}}[\mathrm{mrad}]$ & $\mathrm{S}_{\mathrm{k}}[\mathrm{kNm} / \mathrm{rad}]$ \\
\hline $3^{+}$ & -1.8 & -40.1 & 130 \\
\hline $2^{+}$ & -3.0 & -30.9 & 10 \\
\hline $1^{+}$ & -2.8 & -9.1 & 300 \\
\hline $1^{-}$ & 0.9 & 6.0 & 150 \\
\hline $2^{-}$ & 1.2 & 18.8 & 25 \\
\hline $3^{-}$ & 0.5 & 40.0 & 30 \\
\hline
\end{tabular}

Figure 8. The considered moment - rotation relationship for the beam-to-column joints.

At first, the load carrying capacity under static loads has been evaluated. As to the ultimate limit state (SLU), the General Method has been iteratively applied. Design is governed by the resistance of the pallet beams and $\mathrm{W}_{\mathrm{ST}}=4.60 \mathrm{~N} / \mathrm{mm}$ represents the maximum design value of the uniformly distributed load on each pallet beam, corresponding to a nominal design mass sustained by each upright frame that is equal to approximately $10000 \mathrm{~kg}$. W pallet beam deflection is always lower than the design limit, which is taken as $13.5 \mathrm{~mm}$ (corresponding to $1 / 200$ of the beam length).

As already discussed, the monotonic joint curve is usually adopted for seismic design according to the LFMA, MRSA and NSPA approaches, all of them neglecting the actual joint response under reverse cyclic moments. With the scope of the present study being a general appraisal of the benefits associated with the NLTH-LCF approach, two cyclic joints models, differing in terms of the deterioration of the rotational stiffness, have been considered. Both joint models are characterized by the possibility to account for the reduction of the flexural strength due to the presence of softening branches in the M- $\Phi$ curve. In particular, it is worth pointing out that:

- the first model, that is identified as EPK, reproduces an elasto-plastic constitutive law with kinematic strain-hardening. As shown in figure 9a), unloading and reloading phases are governed by the monotonic response and hence the form of the cycle appears stable with a more than satisfactory energy absorption capability. If the joint response is in the softening phase, the associated value of the bending moment immediately before unloading represents the new limit for the flexural resistance in the subsequent cycle. It is worth mentioning that this type of cyclic response can be obtained in practice by adding bolts connecting the brackets of the pallet beam to the upright [32]. However, this reflects an additional cost that may not be accepted by manufactures and owners; 
- the second model, which in the following is identified as ACP, is the typical Pivot-model [47] already used in a numerical study on racks [48]. Here it has been applied in a simplified way to take into account of the stiffness degradation in the loading phase. In addition to the knowledge of the monotonic M- $\Phi$ joint curve, the values of $\alpha^{+}$and $\alpha^{-}$, both assumed equal to 1.5 , are required. The intersection between the horizontal lines at $\alpha^{+} \mathrm{M}^{1+}$ and $\alpha^{-} \mathrm{M}^{1-}$ with the initial stiffness straight lines identify the $\mathrm{P}^{+}$and $\mathrm{P}^{-}$pointer points, respectively, that are used to define the slope of the unloading branches. After the first half-cycle for hogging moments $(\mathrm{OAB})$, the unloading phase is represented by the $\mathrm{BC}$ line, defined by points $\mathrm{B}$ and $\mathrm{P}^{+}$until the bending moment reduces to zero (point $\mathrm{C}$ ) and then is followed by a slippage branch (CO). Similarly, in the case of sagging moments, initially the elastic (OD) and plastic (DE) loading branches are based on the monotonic response. Unloading (branch EF) is along the $\mathrm{EP}^{-}$line until zero moment (point F), followed by slippage to the origin (branch FO). As to the subsequent half-cycle, the hogging reloading branch is characterized by a reduced stiffness that is based on the last point reached in the previous hogging half-cycles and in correspondence with the bending moment value previously reached (point B). Reloading is then along the line $\mathrm{BG}$, where in this case $\mathrm{G}$ in fact lies on the softening branch. Unloading is represented by the branch from $\mathrm{G}$ to $\mathrm{H}$ (along the line $\mathrm{GP}^{+}$) followed by slippage until the origin (HO).

As to the fatigue resistance, a value of $\mathrm{K}_{\mathrm{BCC}}=10^{6} \mathrm{rad}^{3}$ has been assumed to characterize the cyclic performance of the beam-to-column joints. It is worth noting that this value is based on the Authors' expertise and is considered acceptable given that the aim of the present section is to show the general procedure. It should not be used as a reference value for everyday practice.
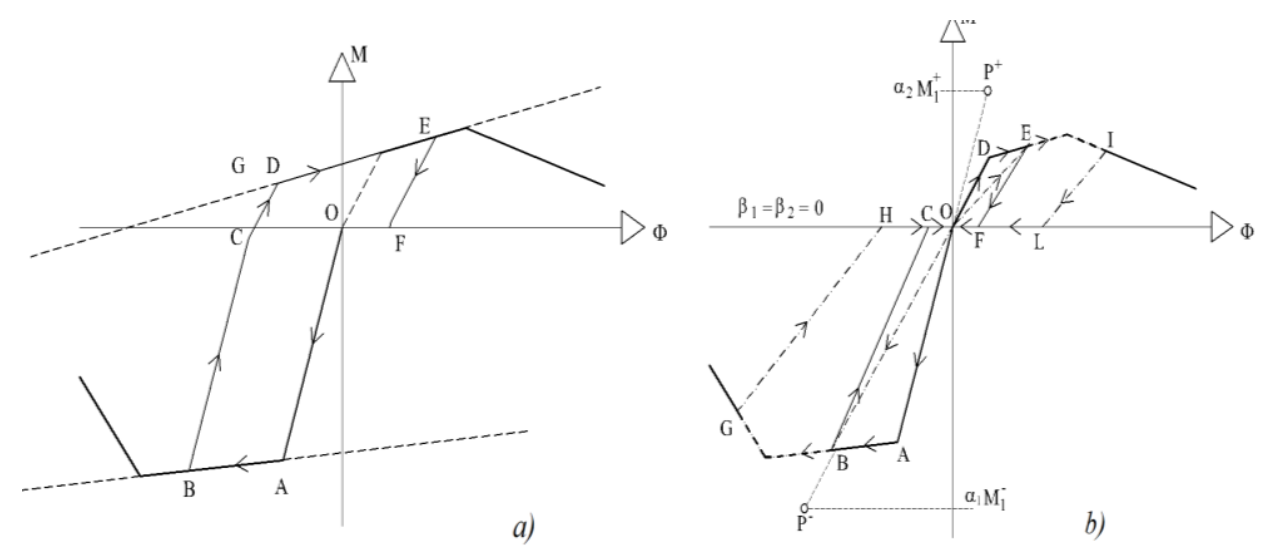

Figure 9. Cyclic response according to the type EPK (a) and ACP (b) joint model.

For the seismic non-linear analyses, two different locations in Italy have been considered where earthquakes recently occurred. The two locations are: Mantua (2012-Lombardy, ground type D, topography class T2 and PGA=0.20g) and L'Aquila (2009-Abruzzo, ground type C, topography 
class $\mathrm{T} 2$ and $\mathrm{PGA}=0.40 \mathrm{~g}$ ). In both locations the aforementioned earthquakes resulted in loss of life and significant economic losses. Elastic spectra have been defined in accordance with the Italian code for structural building design (NTC2008 [49]). Starting from the elastic spectrum of the sites, a synthetic ground motion spectrum-compatible earthquake has been generated and used as input for the NLTH analysis, assuming that takes a period of 20s $\left(t_{\max }=20 s\right)$. The well-known program SIMQKE [50] can be efficiently used to generate groups of stationary artificial record such as they fit the target spectrum. Despite the code requirements related to the number of acclerograms, in the following reference is made to one accelerogram, being the scope of the paper the discussion of the proposed procedure. Figure 10 shows the used accelerogram, which fully satisfies the EC8 requirements on the limit associated with the difference in terms of peak-to-valley variability, for each considered seismic zone.

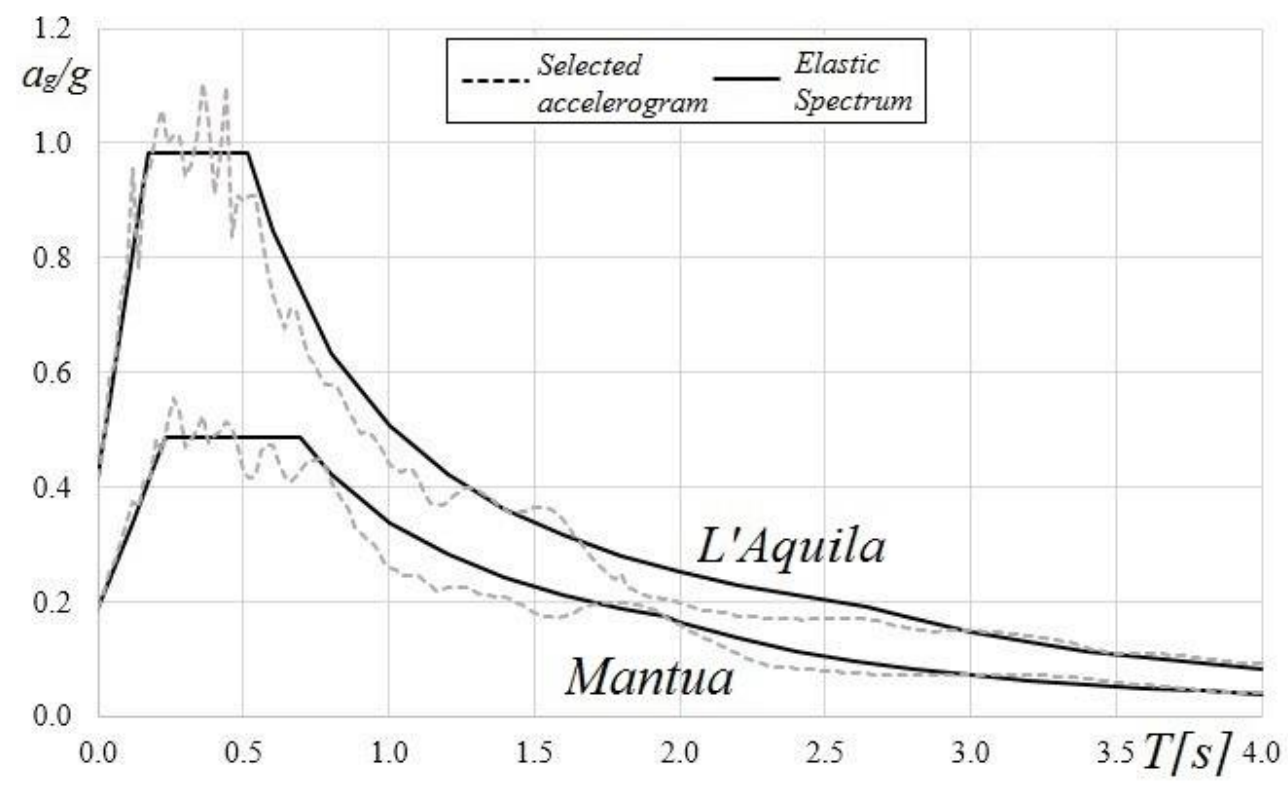

Figure 10. Elastic spectrum of the considered earthquakes [28].

The NLTH analyses have been carried out by means of a commercial non-linear FE analysis package (SAP2000v.17 [51]) and the members have been assumed to have a linear elastic response. As to the seismic design load, the value of gravity load simulating the effects of the pallet units was assumed equal to $W_{\text {SEIS }}=3.50 \mathrm{~N} / \mathrm{mm}$ distributed on each pallet beam, corresponding approximately to $70 \%$ of the static load carrying capacity. It is worth noting that the gravity load has a strong influence on the dynamic response of rack frame, but a complete parametric analysis on its influence is beyond the scope of this numerical example.

\subsection{Analysis results}

For the first part of this investigation the Safety Index for each member has been evaluated for the entire duration of each ground motion. The results for the critical uprights are shown in figure 11. In 
particular, the effects of the two considered earthquakes can be directly compared, along with a comparison of the adopted cyclic joint models.

\section{L'Aquila}
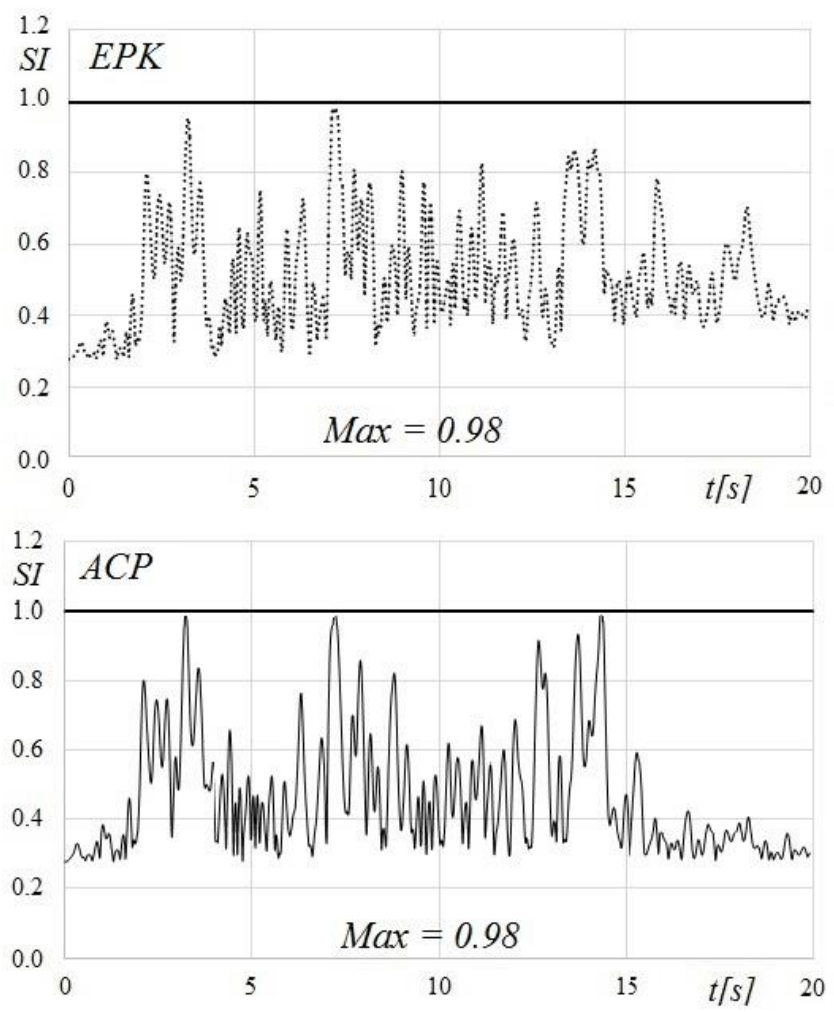

Mantua
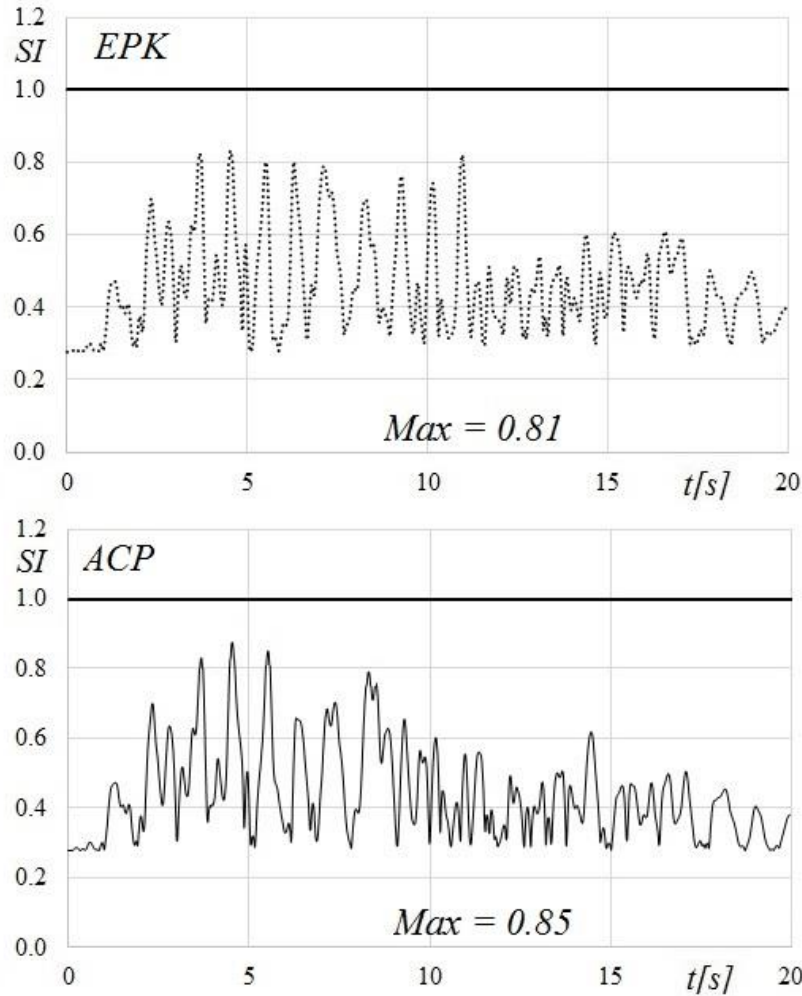

Figure 11. Safety Index of the most highly stressed member during the earthquakes.

It can be noted that the maximum SI is never greater than unity. This shows that the rack is able to resist to both earthquakes, independent of the cyclic joint model considered. In the case of the L'Aquila earthquake, the value of the considered vertical load is close to the maximum permissible load for the considered earthquake, with $\mathrm{SI}=0.98$. As to the Mantua earthquake, the value of the maximum SI is slightly lower. This means that the vertical load could be increased; however, only a moderate (approximately 10\%) increase can be achieved, despite the design intensity at Mantua being significantly less. Furthermore, figure 11 makes reference to an internal upright located in the first span. This upright can however be considered representative of all other internal columns at the same storage level. As to the pallet beams, for the most severe earthquake results in maximum SI values of 0.92 and 0.95 for the EPK and ACP models, respectively, which are related to an external beam at the second storage level. In case of the Mantua earthquake the corresponding values are 0.78 and 0.81 .

Attention has then been focused on the damage accumulation process and as an example figure 12 presents the trend of the damage, expressed in percentage terms, versus duration of ground shaking. It is worth mentioning that in the following, for the sake of simplicity, the data refer to the 
components on the front down-aisle side, but are practically always equal to the corresponding components of the back side. The most damaged joint in each storage level always corresponds to an external upright: solid and dashed lines are related to the EPK and ACP models, respectively. The first parts of the earthquakes (up to $3 \mathrm{~s}$ ) do not cause any relevant damage to the joints. The greatest plastic excursions in the joints occur in the range of 3-15s, as can observed from the slope of the D-t curves. Furthermore, it can be noted that the damage appraised via the ACP model is slightly less than for the EPK model.

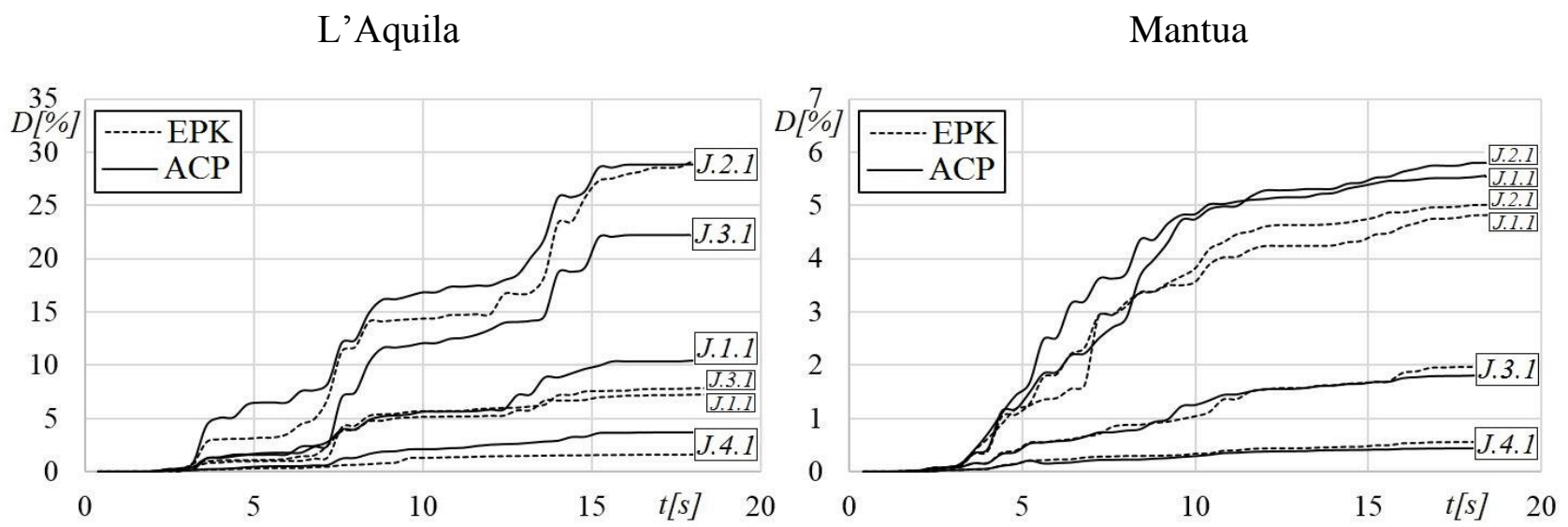

Figure 12. Accumulation of damage (\%) during the considered earthquaks.

Figure 13 presents the values of the total damage on the whole structure after earthquake. It can be noted, independent of the approach used to model the cyclic joint response, that:

- the damage index is maximum at the second storage level and decreases towards the top, where it is practically equal to zero;

- joints to external uprights are always more highly damaged than the joints of internal uprights. For each pallet beam, the damage indices at the joints have significant differences due to the presence of hogging moments associated with gravity loads;

- the damage indices of joints connecting to internal pallet beams are quite similar within a given level;

- the joint model influences the value of the accumulated damage. $\mathrm{D}$ values associated with the ACP model are lower than those for the EPK model.

Furthermore, from an overall view of the data it is confirmed that the ACP joint model leads to slightly larger values of the accumulated damage index $D$. with the maximum differences being up to $40 \%$ and $20 \%$ for the L'Aquila and Mantua earthquakes, respectively. The values of the damage index associated with the NLTH analysis are of great interest for practical design purposes and hence they have been are summarized, with reference to all the joints of the rack (i.e. on the front 
and back down-aisle plane), in table 1. For each design case, the damage index value, in terms of mean value for each storage level and mean value for the overall rack, is presented.
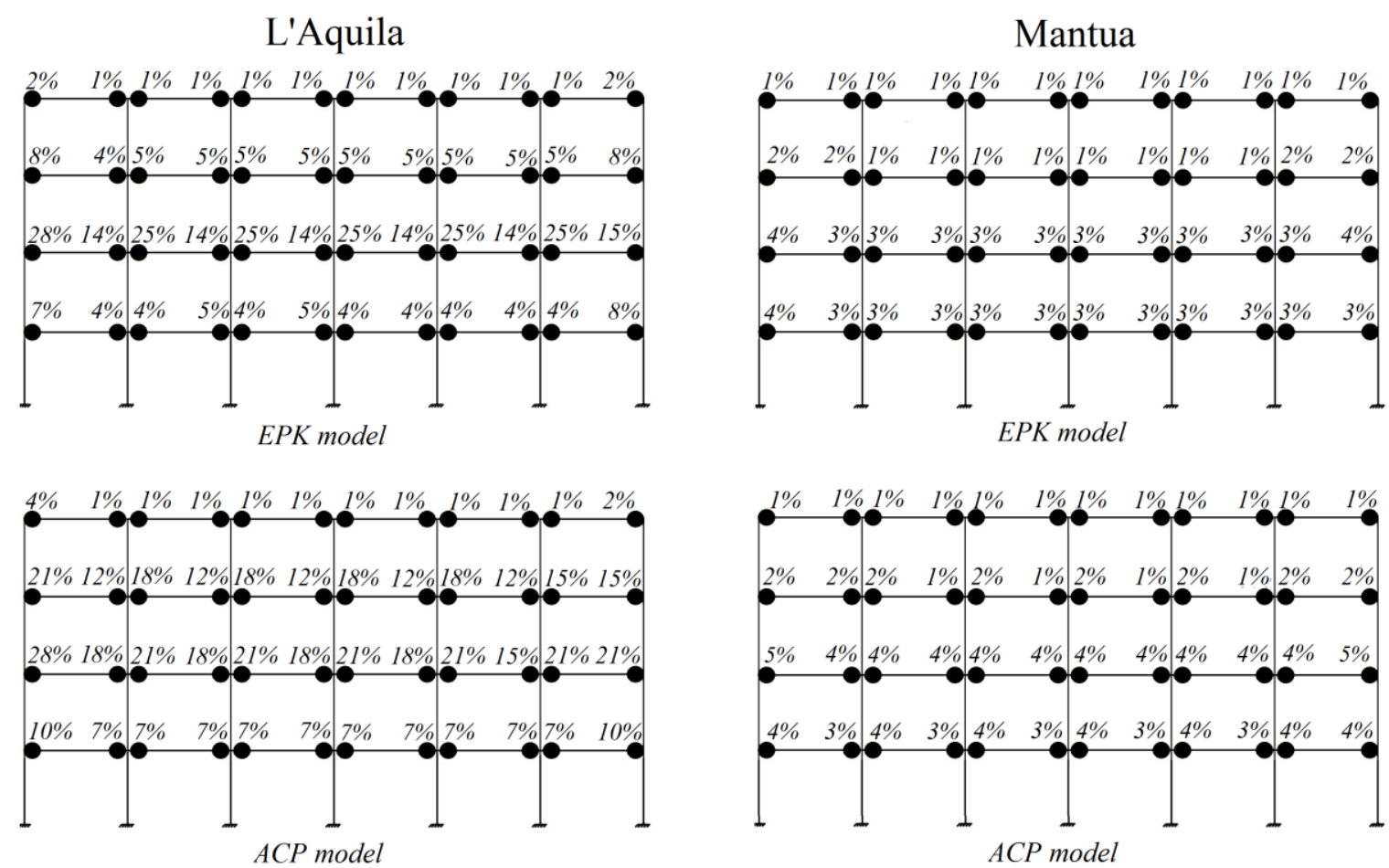

Figure 13. Damage index distribution (in percentage).

An analysis of the different effects due to the considered ground motions shows that, in the case of the Mantua earthquake the accumulated damage can be considered negligible for practical design purposes. On the other hand, the L'Aquila earthquake leads to a non-negligible value at the second storage level (D >20\%) with both joint models and at the third storage level (D 5\%) with the sole ACP model.

Table 1. Mean damage index in percentage for each storage level and for the overall rack.

\begin{tabular}{|c|c|c|c|c|c|c|}
\hline Earthquake & Joint model & I level & II level & III level & IV level & mean \\
\hline \multirow{2}{*}{ L'Aquila } & EPK & 4.80 & 19.64 & 5.21 & 1.09 & 7.68 \\
\cline { 2 - 7 } & ACP & 7.50 & 20.57 & 15.21 & 1.60 & 11.22 \\
\hline \multirow{2}{*}{ Mantua } & EPK & 3.14 & 3.39 & 1.49 & 0.89 & 2.08 \\
\cline { 2 - 7 } & ACP & 4.03 & 4.23 & 1.59 & 0.95 & 2.53 \\
\hline
\end{tabular}

\subsection{Assessment of the rack performance}

The last aspect of paramount importance is related to the safe usage of the racks after the earthquake, i.e. how to account for the effects of strength (EPK model) and strength and stiffness (ACP model) reduction. For the EPK model, figure 13 can be considered, which presents the typical cyclic response associated with the considered earthquakes. It is worth mentioning that only for a 
few joints (like the one considered in the figure) the reduction of the resistance can be appraised. In particular, in the case of the L'Aquila earthquake a reduction in flexural joint resistance is observed at the second storage level, with reductions of approximately $33 \%$ and $45 \%$ for sagging and hogging moments, respectively. For the other levels, cyclic joint response was within the elastic or post-elastic phase but without go into the softening branches.

L'Aquila

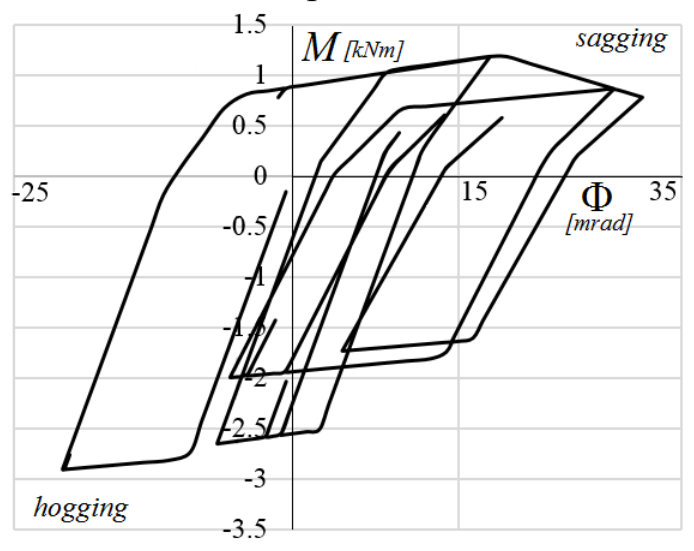

Mantua

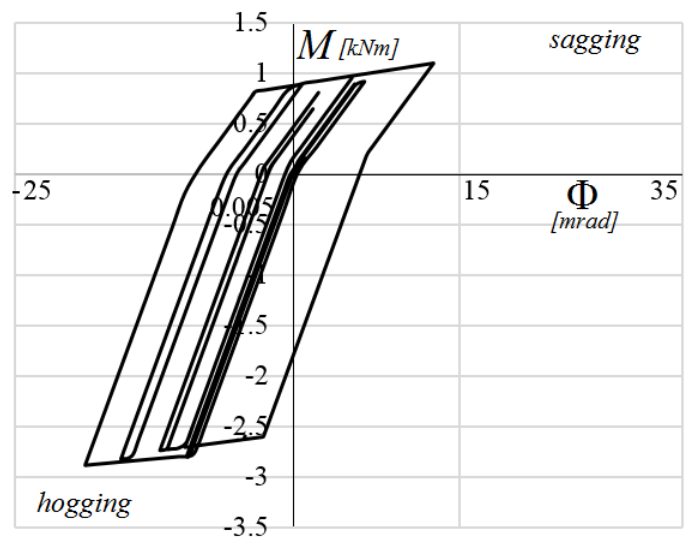

Figure 14. Cyclic response of joint J.2.2 by considering EPK joint mode1.

As to the typical cyclic response of the second joint model, which is able to simulate more accurately the cyclic joint response, reference can be made to figure 15 . In the figure the M- $\Phi$ curve for a joint to an external upright at the second storage level (joint J.2.1) is shown. These curves are however fully representative of the behavior observed in all the rack joints. A comparison between the responses allows for a direct appraisal of the effects associated with most severe earthquake, especially for hogging moments.

\section{L'Aquila}

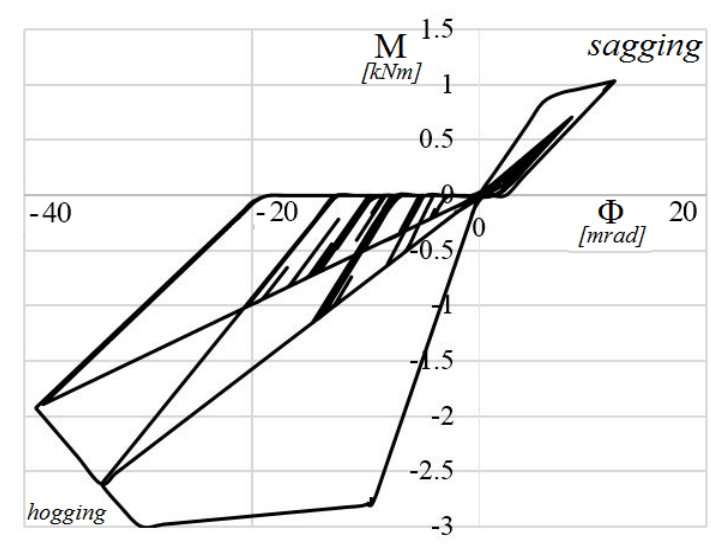

Mantua

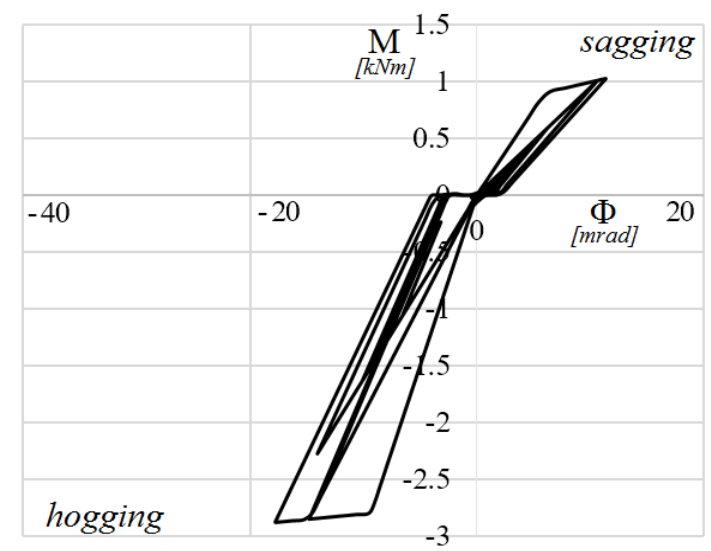

Figure 15. Cyclic response of joint J.2.1 by considering ACP joint model.

As to the reduction of flexural strength, reference can be made to figure 16, which shows the results for the L'Aquila earthquake. Unlike the analyses with the EPK model, the ACP model results in the 
joints at the third storage level (in addition to those of the second level) being pushed into the softening branches. Joints at the first and fourth levels experience no reduction in strength.

sagging

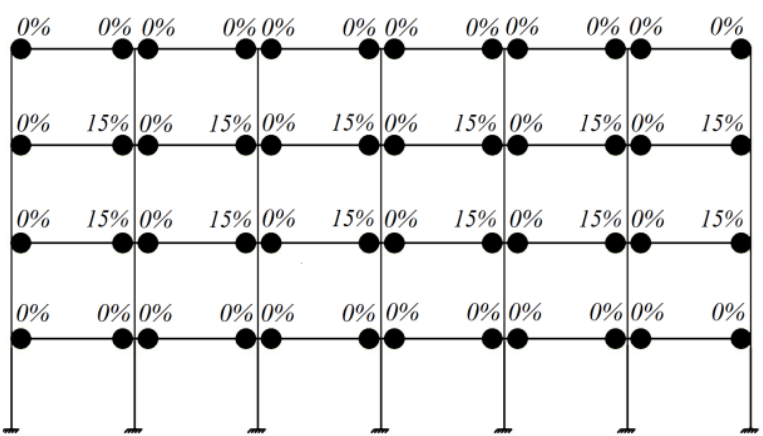

hogging

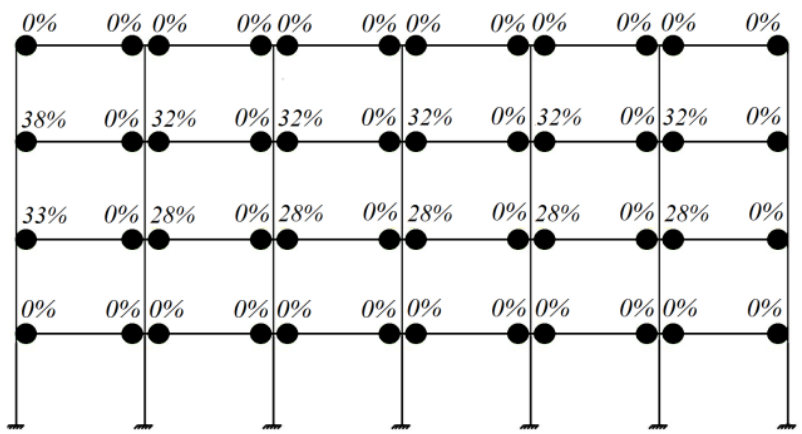

Figure 16. Strength reduction after L'Aquila earthquake ACP model.

Furthermore, from figure 15, it appears that the joint response is characterized by a non-negligible decrement of the joint stiffness, as it can be directly appraised from figure 17, which is referred to the most highly stressed joint (joint J.2.1). In particular, the ratio of the actual stiffness over the elastic monotonic one is plotted versus the time, representing the earthquake evolution, with reference to both sagging and hogging moments.

\section{L'Aquila}

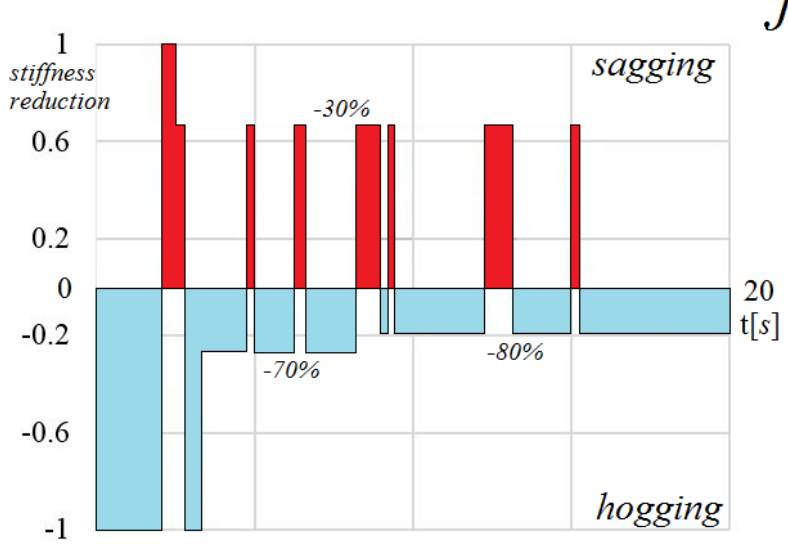

Mantua

$J .2 .1$

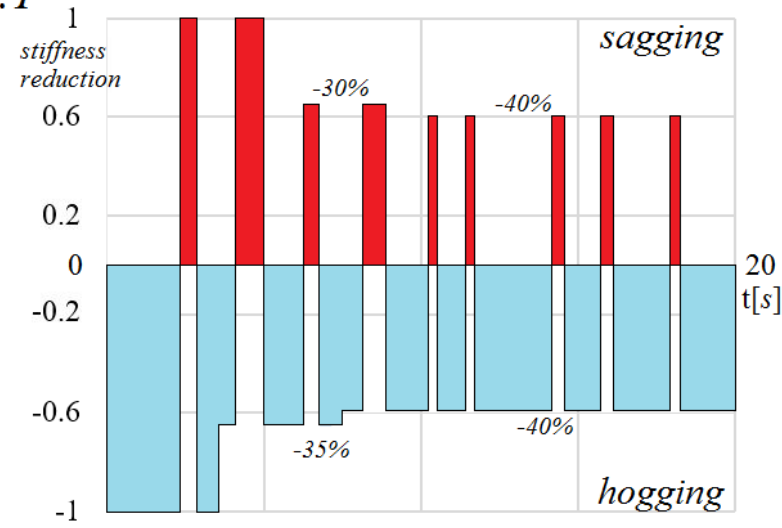

Figure 17. Stiffness reduction during the considered earthquakes of ACP joint model.

Similar remarks can be proposed with reference to the other joints and reference can be made to figure 18 in order to get a general overview of the stiffness reduction on the racks. In the figure, for each joint on one of the down-aisle planes, the reduction of the initial stiffness is expressed as a percentage for sagging and hogging moments associated with the considered ground motions. In particular, it can be noted that:

- the maximum reduction is observed at the second storage level, which is as expected given the previous observations regarding maximum damage; 
- in each pallet beam, the reductions in flexural stiffness at different ends of the span are remarkably different due to the presence of hogging moments for static loads;

- maximum stiffness reductions are associated with the L'Aquila earthquake, which are more than twice those observed for the Mantua earthquake.

L'Aquila
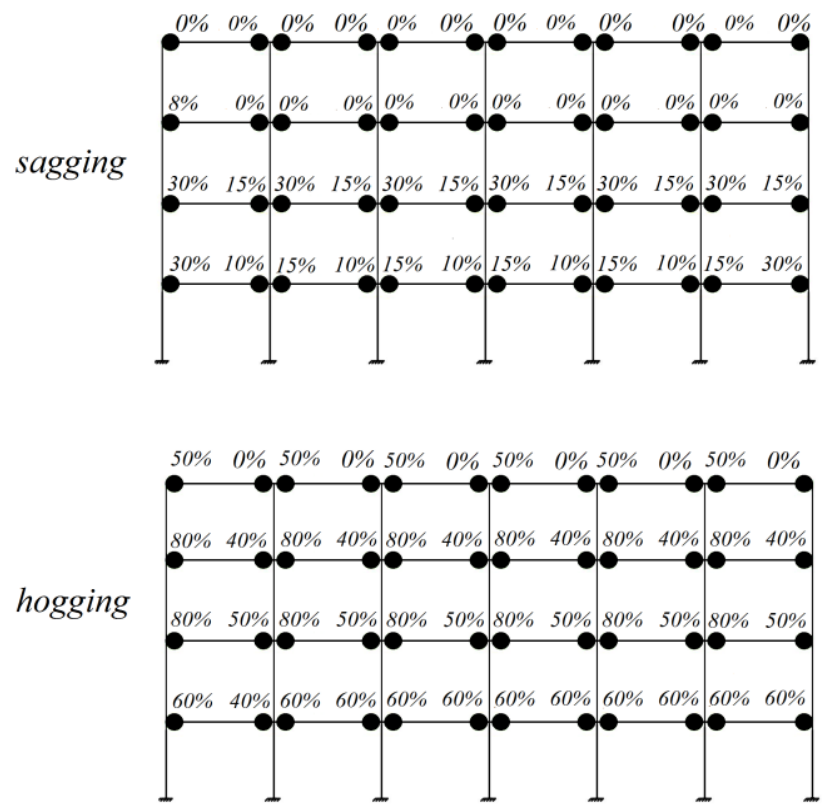

Mantua
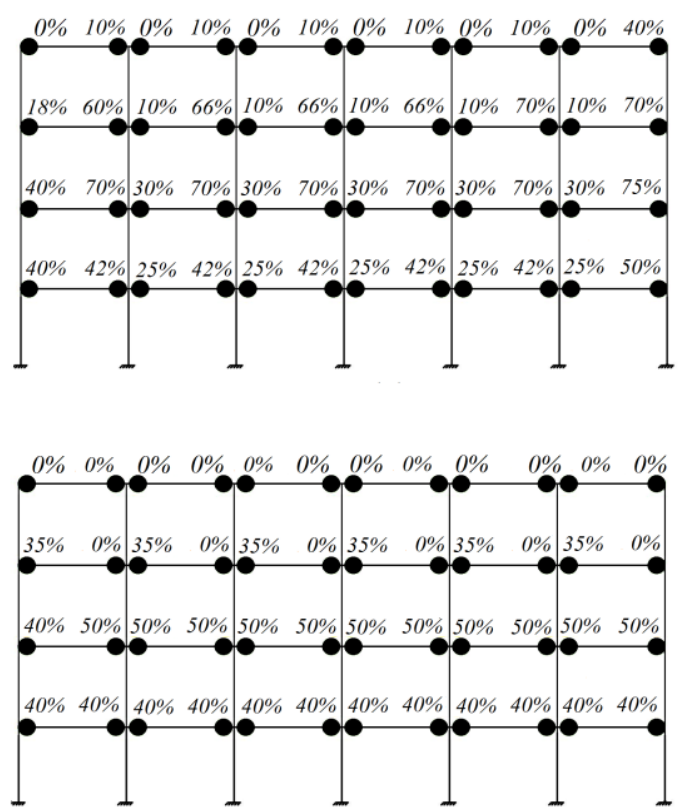

Figure 18. Stiffness reduction associate with ACP model after earthquake.

As a summary of the actual joint performance after earthquake, table 2, which is for the ACP joint model only, presents the key data related to the effective performance of the considered rack. The data is presented in terms of mean value of the reduction of stiffness and strength for each floor level and for the overall frame. It is worth noting that according to the practice followed by rack engineers, after each earthquake, only very limited checks are carried out to evaluate structural damage, generally based on visual inspection and/or a direct evaluation of the out-of-plumb of the uprights. The observations that can be made with the proposed design strategy are quite impressive because, despite the fact that the rack resists a given ground motion and hence it appears apparently safe, significantly weaker and more flexible joints govern the rack response after earthquake. In particular, it can be noted that the stiffness reduction is never negligible from the design point of view, independent of the PGA, especially at the second storage level, as expected, where the greatest values of damage index D were observed. More limited effects can be noted with reference to the mean strength reduction, never observed for the Mantua earthquake and however for L'Aquila earthquake not greater than $17 \%$ on the second storage level and with a mean value referred to the whole rack of $8 \%$. 
Table 2. Mean value of the stiffness and strength reduction for each storage level and for the whole rack (ACP joint).

\begin{tabular}{|c|c|l|c|c|c|c|c|}
\hline Earthquake & \multicolumn{2}{|c|}{ joint parameter } & I level & II level & III level & IV level & mean \\
\hline \multirow{3}{*}{ L'Aquila } & \multirow{2}{*}{ sagging } & stiffness & $36 \%$ & $51 \%$ & $35 \%$ & $5 \%$ & $32 \%$ \\
\cline { 2 - 8 } & & strength & $0 \%$ & $15 \%$ & $15 \%$ & $0 \%$ & $8 \%$ \\
\cline { 2 - 8 } & \multirow{2}{*}{ hogging } & stiffness & $60 \%$ & $64 \%$ & $62 \%$ & $27 \%$ & $53 \%$ \\
\cline { 3 - 8 } & strength & $0 \%$ & $15 \%$ & $17 \%$ & $0 \%$ & $8 \%$ \\
\hline \multirow{3}{*}{ Mantua } & \multirow{2}{*}{ sagging } & stiffness & $15 \%$ & $22 \%$ & $1 \%$ & $0 \%$ & $10 \%$ \\
\cline { 3 - 8 } & strength & $0 \%$ & $0 \%$ & $0 \%$ & $0 \%$ & $0 \%$ \\
\cline { 2 - 8 } & \multirow{2}{*}{ hogging } & stiffness & $40 \%$ & $48 \%$ & $18 \%$ & $0 \%$ & $27 \%$ \\
\cline { 3 - 8 } & strength & $0 \%$ & $0 \%$ & $0 \%$ & $0 \%$ & $0 \%$ \\
\hline
\end{tabular}

Owing to the relevant reduction of the joint behavioural parameter, a further step to achieve the goal of a safe rack design is required, which consists of the evaluation of the effective load carrying capacity based on the actual value of the monotonic joint performance after it has been reduced by an earthquake ground motion. In the following, attention is paid to the results associated with the ACP joint models, which allows for more severe earthquake effects due to the ACP model allow for a more significant strength reduction than the EPK. Having observed the non-negligible mean values presented in table 2, it appears that a new check is required to evaluate if the post-earthquake rack capacity is sufficient for resisting the pallet beam load of $3.5 \mathrm{~N} / \mathrm{mm}\left(\mathrm{W}_{\text {SEIS }}\right)$. As a consequence, the rack must be re-analysed. Two options for the new analyses should be adopted by designers to update the mesh accounting for the actual joint characteristics:

a) model the rack by updating each beam-to-column joint $M-\Phi$ curve with the actual value of the stiffness and the strength for hogging and sagging moments. This approach takes a lot of time to prepare the rack mesh because it is necessary to define the updated behavioural parameters for each joint;

b) model the rack by adopting for all joints of the same storage level a mean M- $\Phi$ curve deduced from the data of table 2. In this case the time required to update the joint characteristics is significantly reduced as during the input phase it is possible to define families of joints having equal mechanical properties. As an example, figure 19 presents the constitutive laws adopted for each storage level, for both the L'Aquila (a) and Mantua (b) cases in the required checks for post-earthquake performance. 
L'Aquila

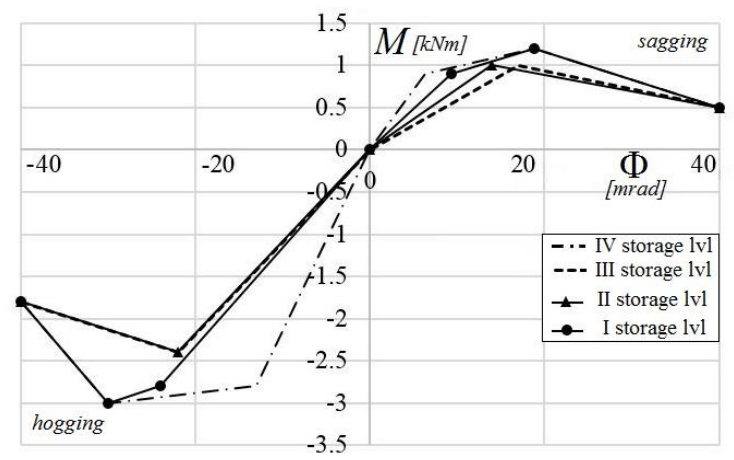

Mantua

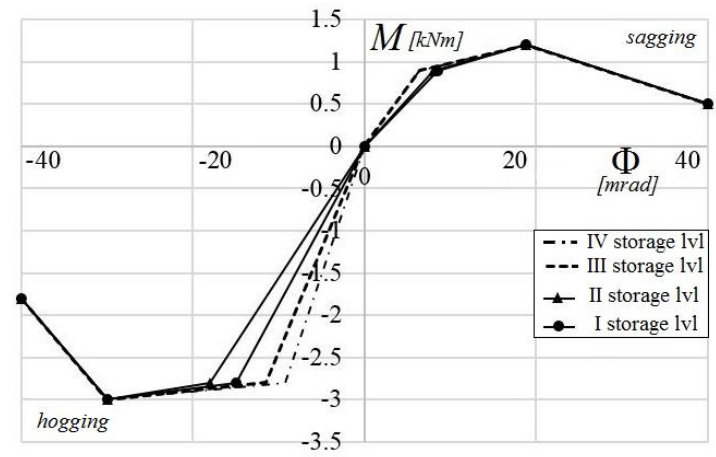

Figure 19. Joint laws for each storage level after earthquake.

Key results of these new sets of analyses are summarized for model a) in table 3, which also presents the data related to the approach of using the same constitute joint law per floor between brackets (model b) together with the design data before earthquake. In particular, it can be noted that, owing to the ground motion and with reference to the pre-earthquake values:

- the critical load buckling multiplier $\left(\alpha_{\mathrm{cr}}\right)$ reduces to $46 \%$ (case a) and $22 \%$ (case b);

- the fundamental period of vibration $\left(\mathrm{T}_{1}\right)$ increases to $37 \%$ (case a) and $30 \%$ (case b);

- the SI values, which are detailed with reference to the ultimate load multiplier for uprights $\left(\alpha_{\mathrm{ultk}, \mathrm{u}}\right)$, joints $\left(\alpha_{\mathrm{ultk}, \mathrm{j}}\right)$ and pallet beams $\left(\alpha_{\mathrm{ultk}, \mathrm{pb}}\right)$ increase remarkably: up to $35 \%$ and $24 \%$ for the rack model a) and b), respectively;

- the beam deflection increases significantly, as expected from the joint stiffness reduction; however, the associated SI values are not relevant for design purposes.

Finally, it can be noted that with SI being greater than unity after the L'Aquila earthquake, independent of the degree of accuracy in reproducing the actual joint behavior, the load carrying capacity has to be reduced and the effective distributed load on the pallet beams decreases to values of $3.03 \mathrm{~N} / \mathrm{mm}$ for the more refined mesh and to $3.40 \mathrm{~N} / \mathrm{mm}$ for the rack model with equal joint properties in each given storage level. Even though the reduction in load carrying capacity may be not great it may still present significant issue for owners in terms of ability to store their goods and products for which the racks has been specifically designed. As an alternative to accepting a reduction of the rack load carrying capacity, retrofit of the damaged components could instead be an attractive option. In the considered cases, owing to the aforementioned remarks related to the earthquake effects, two different solutions have been considered that involve replacing of the pallet beams i) at the second storage level and ii) at the second and third storage levels. Results associated with the retrofitted analyses, which are reported in table 3, show that the influence of the third storage level is quite limited and hence, to guarantee the required rack performance, the solution to change the pallet beams at only second storage level appears cheap and efficient. 
Table 3. Influence of the cyclic joint deterioration on the effective rack performance.

\begin{tabular}{|c|c|c|c|c|c|}
\cline { 3 - 6 } \multicolumn{1}{c|}{} & \multirow{2}{*}{$\begin{array}{c}\text { Before } \\
\text { earthquake }\end{array}$} & \multicolumn{2}{c|}{ After earthquake } & \multicolumn{2}{c|}{ Retrofit for L'Aquila damage } \\
\cline { 3 - 6 } & & & Mantua & $\begin{array}{c}2^{\text {nd }} \text { storage } \\
\text { level }\end{array}$ & $\begin{array}{c}2^{\text {nd }} \text { and } 3^{\text {rd }} \\
\text { storage level }\end{array}$ \\
\hline buckling multiplier & 4.50 & $2.45(2.70)$ & $3.55(3.75)$ & 3.52 & 3.61 \\
\hline Fundamental period & $2.07 s$ & $3.3 s(2.73 s)$ & $2.94 s(2.06)$ & $2.45 s$ & $2.25 s$ \\
\hline$\alpha_{\text {ultk,u }}$ & 3.298 & $3.109(3.221)$ & $3.236(3.331)$ & 3.109 & 3.108 \\
\hline$\alpha_{\text {ultk,j }}$ & 1.622 & $1.126(1.398)$ & $2.005(2.055)$ & 1.622 & 1.621 \\
\hline$\alpha_{\text {ultk,pb }}$ & 1.572 & $1.078(1.224)$ & $1.196(1.293)$ & 1.419 & 1.518 \\
\hline SI & 0.756 & $1.154(1.023)$ & $0.987(0.921)$ & 0.938 & 0.921 \\
\hline Serviceability limit & 0.33 & $0.51(0.49)$ & $0.47(0.36)$ & 0.33 & 0.33 \\
\hline
\end{tabular}

\section{PRELIMINARY CONCLUSIONS AND FUTURE DEVELOPMENTS}

Steel storage pallet racks, which are used extensively worldwide for the storage of goods and products, behave like moment-resisting frames for which inelastic behavior is associated only with joints. The seismic design approaches currently adopted in daily practice are based on the reduction of the elastic spectrum to the design spectrum via the use of behavior or q- factor (Fig. 3) and suffer from some of the following defects:

1) they are derived from the approaches proposed for more conventional steel buildings. The qvalue proposed for all the structures that can be classified as pallet racks is independent of the geometry, the component performance and the load condition, which are all factors influencing rack behavior. Furthermore, to base the design on the monotonic joint behavior seems correct only in absence of slippage and pinching in the cyclic response, which have both been experimentally observed and cannot be neglected for practical design purposes;

2) they neglect the fatigue effects in critical components such as joints, i.e. it is assumed an unlimited fatigue life of the components;

3) they are unable to account for the effective post-earthquake rack performance, which is dependent on the deterioration of strength and stiffness of the joints under reverse cyclic loading.

The reasonably efficient NLTH-LCF procedure has been proposed for the design of storage pallet racks in seismic zones and combines traditional time-history (NLTH) analysis with low-cycle fatigue (LCF) theory. This procedure allows for adequately solving the critical issues associated with the aforementioned points 1-3 that are currently neglected into routine rack design. Furthermore, it could be easily adopted by designers because it is based on the use of commercially available non-linear finite element analysis software. A case-study example has been discussed to show how, in addition to the evaluation of the accumulated damaged in each joint (i.e. the direct assessment of the residual life after earthquakes), the actual load carrying capacity of racks must be 
re-evaluated if the joints are characterized by the reduction of stiffness and strength due to the effects of the excursion into the plastic range.

Despite the fact that the proposed case is to focus attention on the key features of the procedure, with it developed in reference to two different joints models, it is possible to evaluate also the additional parameters useful for designers to better define the conditions for a safer in-service use of rack frames. In particular, it has also been shown that in the case of severe earthquakes, the ground motion effects reducing rack performance can be balanced by replacing the most damaged pallet beams.

It is worth noting that the content of the present paper is intended serve as a preliminary explorative study. More activities have been planned in the near future by the Authors to characterize the rack joints (from the low-cycle fatigue point of view) in order to better define the fatigue resistance life as well as the deterioration on stiffness and strength due to the plastic deformations. 


\section{REFERENCES}

[1] Peköz T., Winter G., "Cold-formed steel racks structures”, 2nd edition, St Louis, MO, USA, (1973).

[2] Dubina D., Ungureanu V., Landolfo R., "Design of Cold-formed Steel Structures, Eurocode 3: Design of Steel Structures, Part 1-3 - Design of Cold-formed Steel Structures", 1st edition, Wiley-Blackwell, Hoboken, NJ, (2012).

[3] Tilburgs K., Those peculiar structures in cold formed steel: "racking and shelving", Steel Construction 6 (n. 2), pp. 95-106, (2013).

[4] Markazi F.D., Beale R.G., Godley M.H.R., Experimental analysis of semi-rigid boltless connectors, Thin-Walled Structures 28, pp. 57-87, (1997).

[5] Baldassino N. and Bernuzzi C., Analysis and behavior of steel storage pallet racks, Thin Walled Structures 37 (4), pp. 277-304, (2000).

[6] Casafont M., Pastor M., Roure F., Bonada J., and Pekoz T., Distortional buckling test for steel storage rack columns, Proceedings of the institution of Civil Engineers: Structures and Buildings 166, Issue 8, pp. 392-402, (2013).

[7] Yang D., Hancock G. J., Compression tests of high strength steel channel columns with interaction between local and distortional buckling, Journal of Structural Engineering 130, Issue 12, (2004).

[8] Teh L.H., Hancock G.J., Clarke M.J., Analysis and design of double sided high-rise steel pallet rack frames, Journal of Structural Engineering 130: 1011-21, (2004).

[9] Zhang X., Rasmussen K.J.R., Zhang H., "Formulation and implementation of threedimensional doubly symmetric beam finite elements with warping effects in opensees", Proceedings of seventh International Conference in Advances in Steel Structures, Nanjing, China, (2012).

[10]Bernuzzi C., Pieri A., Squadrito V., Warping Influence on the static design of unbraced steel storage pallet racks, Thin-Walled Structures 79, pp. 71-82, (2014).

[11]Chen WF, Atzuta T., "Theory of beam-columns: vol. 2 Space behaviour and design". McGraw Hill, (1977).

[12] Turkalj G, Brnic J, Prpic-Orsic J., Large rotation analysis of elastic thin walled beam type structures using ESA approach, Computer and Structures 81, pp. 1851-64, (2003).

[13] Battini J. M., "Co-rotational beam elements in instability problems". Technical report from Royal Institute of Technology Department of Mechanics — Stockholm, Sweden; January (2002).

[14] Shah S.N.R., Ramli Sulong N.H., Jumaat M.Z., Shariati M., State-of-the-art review on the design and performance of steel pallet rack connections, Engineering Failure Analysis 66, pp. 240-258, (2016).

[15] Castiglioni C.A., "Seismic Behavior of Steel Storage Pallet Racking Systems" Springer International Publishing, Berlin, Germany (2016), (ISSN 2198-7300).

[16]Castiglioni C.A., Kanyilmaz A., Angeretti M., Brambilla G., Chiarelli G.P. Bernuzzi C. "Experimental results of full scale push over tests of project SEISRACK2 (seismic behaviour of steel storage pallet racking systems)", 2nd European Conference on Earthquake Engineering, Istanbul Aug. 25-29, (2014). 
[17]Paz M., "Structural Dynamics", Springer, second edition, (1985).

[18]Clough R.W., Penzien J., "Dynamics of Structures”, Mc-Graw Hill, (1993).

[19] Calado L., Castiglioni C.A., "Low Cycle Fatigue Testing of Semi-Rigid Beam-to Column Connections", Proc. of 3rd International Workshop on Connections in Steel Structures, Trento, 28-31 May, pp. 371-380, (1995).

[20]Calado L., Castiglioni C.A., Bernuzzi C., "Cyclic behaviour of structural steel elements. Method for re-elaboration of test data", Proc. of the 1st National Colloquium on Steel and composite Construction, Porto, Portugal, Nov., pp. 633-660, (1997).

[21]Baldassino N., Zandonini R., Design by testing of industrial racks, advanced steel construction 7, No.1, pp. 27-47, (2011).

[22] CEN, (European Committee for Standardization) EN 15512. "Steel static storage systems Adjustable pallet racking systems - Principles for structural design”, (2009).

[23]Federation Européenne de Manutention, "FEM 10.2.02 - recommendations for the design of static steel storage pallet racks", September 2010, version1.00.

[24]European Committee for Standardization CEN, EN1993-1-1, "Eurocode 3 - design of steel structures - part 1-1: general rules and rules for buildings", CEN European Committee for Standardization, (2005).

[25]Federation Européenne de Manutention "FEM 10.2.08, Recommendations for the design of static steel storage pallet racks in seismic conditions", Federation Européenne de Manutention, version 1.00 (2010).

[26]prEN 16681, "Steel static storage systems -Adjustable pallet racking system - Principle for seismic design", CEN European Committee for Standardization (2013).

[27]Chopra A. K., "Dynamics of Structures", Prentice-Hall, International series in Civil Engineering and Engineering Mechanics, $4^{\text {th }}$ edition, (2013).

[28]European Committee for Standardization CEN, "EN 1998-1. Eurocode 8 - Design of structures for earthquake resistance", CEN European Committee for Standardization (2004).

[29] Castellani A., and Faccioli E. "Costruzioni in zona sismica. Metodi di analisi e criteri di progetto. Applicazioni - Aspetti normativi”. II edizione Editore Ulrico, Milano (2000).

[30] Aguirre C., Seismic behavior of rack structures, Journal of constructional steel research 61 pp. 607-624, (2005).

[31]Filiatrault A., Higgins P.S, Wanitkorkul A., Experimental stiffness and seismic response of pallet-type steel storage rack connectors, practice periodical on structural design and construction, august 11(3) 161-170, (2006).

[32] Yin L., Tang G., Zhang M., Wang B., Feng B., Monotonic and cyclic response of speed-lock connections with bolts in storage racks, Engineering Structures 116, pp. 40-55, (2016).

[33]Bernuzzi C., Castiglioni C.A., Experimental analysis on the cyclic behaviour of beam-tocolumn joints in steel storage pallet racks, Thin-Walled Structures, 39, pp. 841-859, (2001).

[34]Zandonini R., Bernuzzi C., Bursi O., "Steel and Steel-concrete composite joints subjected to seismic actions", Proc. of Behaviour of Steel Structures in Seismic Areas, Kyoto, August (1997).

[35]Bernuzzi, C., European and United States Approaches for Steel Storage Pallets Rack Design. Part 1: Discussions and General Comparisons, Thin-walled Structures 97, pp. 308320, (2015). 
[36]Bijlard F, Feldmann M, Naumes J, Sedlacek G. In: Ernst, Sohn, editors. The "general method" for assessing the out-of-plane stability of structural members and frames in comparison with alternative rule in EN 1993 - Eurocode 3 - part 1-1, 3. Steel Construction; 2010 [No. 1].

[37] Papp F. Global stability analysis using general method. www.consteelsoftware.com/

[38]Bernuzzi, C., Draskovic N., Simoncelli M., European and United States Approaches for Steel Storage Pallets Rack Design. Part 2: Practical applications, Thin-walled Structures 97, pp. 321-341, (2015).

[39]RMI (Rack Manufacturers Institute) MH 16.1. "Specification for the Design, Testing and Utilization of Industrial Steel Storage Racks”, pp 59, (2012).

[40]CEN EN 15620, "Steel static storage systems. Adjustable pallet racking. Tolerances, deformations and clearances". (2008).

[41]Bannantine J., Comer J., Handrock., "Fundamentals of metal fatigue analyses", Prentice hall (1989)

[42] International Welding institute JWG XIII-XV "Fatigue recommendations", Doc. XII 153994/XV-845-94 (1994).

[43] Schultz W., A history of fatigue, Engineering fracture mechanics 54 no 2, pp. 263-300, (1996).

[44]European Committee for Standardization CEN, EN1993-1-9, "Eurocode 3 - design of steel structures - part 1-9: Fatigue", CEN European Committee for Standardization (2005).

[45] M.A. Miner, Cumulative damage in fatigue, Journal of applied mechanics, (1945).

[46] CEN EN 10025. "Hot rolled products of structural steels - parts 1-6", (2004).

[47]Dowell R.K, Seible F., Wlson E.L., Pivot hysteresis model for reinforced concrete members, ACI structural Journal September October pp. 607- 617, (1998).

[48] Haque A.B.M.R. and Shahria Alam M. "Preliminary investigation on the Overstrenght and Force reduction factors for industrial Racks Clad Buildings" The $11^{\text {th }}$ Canadian conference on earthquake engineering, July (2015).

[49] NTC 2008- "Norme tecniche per le costruzioni” D.M. 14 Gennaio 2008, Italy, (2008).

[50] Gasparini D.A., Vanmarke E.H., Simulated earthquake motions compatible with prescribed response spectra. MIT civil engineering research report R76-4. Massachusetts Institute of Technology, Cambridge, MA (1976).

[51] $\quad$ www.csiamerica.com/products/sap2000. Version 17.1 (2015). 